\title{
Aplicação de biomarcadores à avaliação de risco ambiental em exposições a hidrocarbonetos policíclicos aromáticos
}

Sérgio Silveira Franco

Dissertação apresentada ao Programa de Pós-Graduação em Saúde Pública para obtenção do título de Mestre em Saúde Pública.

Área de Concentração: Saúde Ambiental Orientador: Profa. Dra. Wanda Maria Risso Günther. 
Autorizo exclusivamente para fins acadêmicos e científicos, a reprodução parcial desta dissertação, por processos fotocopiadores. Ao usá-lo, cite a fonte.

\section{Assinatura:}

Data: 
À minha esposa Juliana. 


\section{AGRADECIMENTOS}

A minha orientadora, Dra. Wanda Maria Risso Günther, pela disposição e empenho, imprescindiveis para realização deste trabalho.

A Dra. Adelaide Cássia Nardocci, por iniciar-me no caminho da avaliação de risco, participando em muitos momentos como co-orientadora, mesmo que de uma maneira informal, durante meu percurso nesta pósgraduação.

Ao Dr. Carlos Celso do Amaral, que muito contribuiu nas discussões a respeito da avaliação de risco.

Aos membros da banca, Dr. Nelson da Cruz Gouveia, Dra. Adelaide Cássia Nardocci e Dra. Wanda Maria Risso Günther pelas sugestões de modificação e pela compreensão quanto a antecipação de data para defesa.

Aos professores do curso de pós-graduação em Saúde Pública, em especial os professores do Departamento de Saúde Ambiental, que colaboraram de maneira fundamental para minha formação.

Ao primo-irmão Roberto Franco Bottini, o Beto, pela acolhida na minha vinda a São Paulo, pela ajuda nas impressões deste trabalho, pelo companheirismo incondicional, em especial pelo estímulo e entusiasmo fundamentais durante muitas ocasiões.

A minha esposa Juliana Cini Perry, pela parceria e cumplicidade incondicionais e indispensáveis em todos os momentos. 


\section{RESUMO}

Estudo de atualização com o objetivo de identificar as principais aplicações de biomarcadores em processos de avaliação de risco ambiental de exposição a hidrocarbonetos policíclicos aromáticos (HPA). Foram apresentados conceitos gerais relativos à exposição aos HPA, à avaliação de risco ambiental e à validação de biomarcadores. Procedeu-se uma análise da literatura internacional atualizada disponivel on line. Identificou-se que a principal razão para utilização de biomarcadores em avaliação de risco é a possibilidade de verificação dos efeitos gerados pela exposição, permitindo direcionar ações de gerenciamento aos agentes biologicamente ativos. Esta abordagem contribui para o entendimento de especificidades locais para as quais, a avaliação de risco ambiental em geral mostra-se insatisfatória. O composto 1-hidroxipireno urinário destaca-se como um marcador confiável de exposição a HPA. Entre os parâmetros genéticos, aberração cromossômica e indução de micronúcleos são citados como marcadores bem fundamentados para aplicação em estudos transversais para caracterização de exposição humana. São necessários mais estudos para que esses parâmetros citogenéticos possam ser utilizados para determinação de causalidade entre exposição aos HPA e ocorrência de danos à saúde. Recomenda-se a utilização integrada de biomarcadores de dose interna e efetiva para diminuição das incertezas das estimativas de exposição. Para dose interna e efetiva, respectivamente, os marcadores 1-hidroxipireno urinário e adutos de DNA-HPA são os mais fundamentados pela literatura atual.

Descritores: Biomarcadores; avaliação de risco; saúde ambiental; hidrocarbonetos policíclicos aromáticos. 


\section{SUMMARY}

Study with the objective identifies the most important applications of biomarkers in environmental risk assessment of polycyclic aromatic hydrocarbons (PAH) exposures. Moreover, it has been presented general concepts related to $\mathrm{PAH}$ expositions, environmental risk assessment and biomarkers validations. An international updated literature was performed using online data base. The results showed that the principal reason to use biomarkers in the risk assessment is the possibility to verify the effects of exposition. Therefore, it allows a directional management to biologically effective agents. This approach contributes to understanding the local specificities when the environmental risk assessment shows unsatisfactory. The urinary 1hidroxipyrene is a secure biomarker to PAH expositions. The cytogenetics parameters chromosomal aberrations (CA) and micronuclei (MN) are well established markers to apply in cross sectional studies in order to characterize human expositions. Currently, more studies are necessary for the use of these cytogenetic biomarkers to verify causalities between $\mathrm{PAH}$ expositions and harmful health effects. It is recommend the integrated use of biomarkers of internal and effective dose to decrease the estimates exposition uncertainties. To internal and effective dose, respectively, the urinary 1-hidroxipyrene and DNA-PAH adducts biomarkers are the most established in the scientific literature.

Key words: biomarkers; risk assessment; environmental health; polycyclic aromatic hydrocarbons. 


\section{LISTA DE ABREVIATURAS}

ATSDR - Agency for Toxic Substances and Disease Registry

CETESB - Companhia de Tecnologia de Saneamento Ambiental CPA - Compostos Policíclicos Aromáticos

DNA - ácido desoxirribonucléico

$\mathrm{EC}_{50}$ - concentração letal para $50 \%$ da população teste

ERL - Electronic Reference Library

FSP/USP - Faculdade de Saúde Pública / Universidade de São Paulo HPA - Hidrocarbonetos Policíclicos Aromáticos

$\mathrm{LD}_{50}$ - dose letal para $50 \%$ da população teste

LOEC - menor concentração com efeitos observáveis

LOEL - menor nível de efeitos observados

MPL - maximum permissible level

NAS - National Academy of Sciences

NEL ou NOEL - no effect level

$\mathrm{NL}$ - negligible level

NOEC - no effect concentration

OMS - Organização Mundial da Saúde

PEC - predicted environmental concentration

PNEC - predicted no effect concentration

PNEL - predicted no effect level

SIBi/USP - Sistema de Bibliotecas da Universidade de São Paulo 


\section{ÍNDICE}

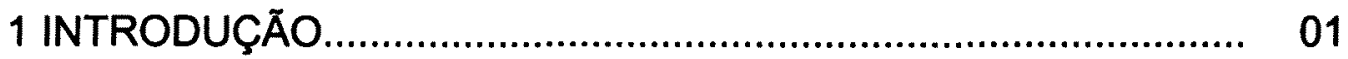

2 OBJETIVOS

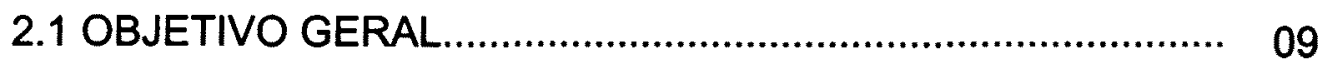

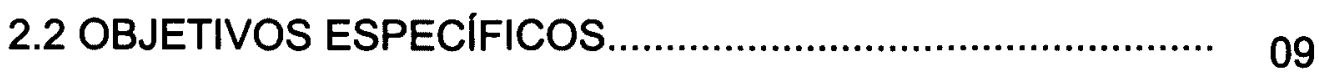

3 MÉTODOS................................................................................. 10

4 HIDROCARBONETOS POLICICLICOS AROMÁTICOS (HPA).... 12

5 CONTAMINAÇÃO POR HPA..................................................... 14

6 AVALIAÇÃO DE RISCO ….................................................... 19

7 BIOMARCADORES E A ANÁLISE DE RISCO............................ 30

7.1 VALIDAÇÃO...................................................................... 34

7.2 ESTUDOS EXPERIMENTAIS, MODELOS ANIMAIS E EXTRAPOLAÇOEES ENTRE ESPÉCIES..................................... 40

7.3 AVALIAÇÃO DE EXPOSIÇÃO E EFEITO DE CONTAMINAÇÃO POR HPA

7.3.1 METABÓLITOS HIDROXILADOS DE HPA BIOMARCADORES DE DOSE INTERNA ............................. 50

7.3.2 ADUTOS DE DNA-HPA - BIOMARCADORES DE DOSE EFETIVA............................................................. 52

7.3.3 ALTERAÇÓES CITOGENÉTICAS BIOMARCADORES DE EFEITO PRECOCE........................... 58

7.3.4 POLIMORFISMO GENÉTICO - BIOMARCADORES DE SUSCETIBILIDADE ...................................................... 61

8 APLICAÇÓES RECENTES E PERSPECTIVAS FUTURAS........... 65

9 CONCLUSÕES ................................................................... 73

10 CONSIDERAÇŐES FINAIS...................................................... 75

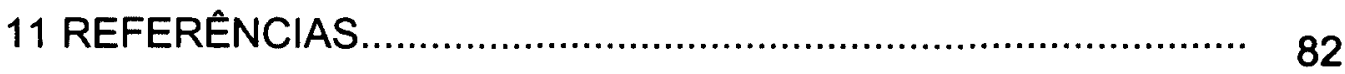




\section{INTRODUÇÃO}

O desenvolvimento generalizado de novas tecnologias, com a automação e o aumento da complexidade dos processos químicos industriais, impulsionados pela concorrência capitalista e a globalização da economia vêm possibilitando operações cada vez mais sofisticadas em ritmos cada vez mais intensos, resultando na expansão da capacidade de produção, armazenamento, circulação e consumo de agentes químicos em âmbito mundial. Tal quadro possibilitou um aumento no consumo de bens, produtos e serviços, fato esse associado por muitos a ganho em qualidade de vida. Por outro lado, esta mudança nos hábitos de consumo tem acrescentado novos riscos a toda a população, pois a velocidade com que essas novas substâncias químicas são introduzidas no ambiente não é acompanhada pelo conhecimento de seus possiveis efeitos deletérios à saúde humana e ao ambiente.

Em centros urbanos, a grande utilização de derivados de petróleo como principal matriz energética relacionada ao transporte tem como conseqüência a intensa formação de hidrocarbonetos policíclicos aromáticos (HPA), que constituem uma das principais classes de contaminantes provenientes das atividades antropogênicas. Além dos problemas diretos da queima de combustivel, deve-se também considerar os riscos relacionados a sua produção, distribuição e armazenamento. Como exemplo desta situação, tem-se no país a questão recente da obrigatoriedade de licenciamento dos postos de gasolina, um dos principais problemas 
ambientais do estado de São Paulo, representando a maioria das áreas incluidas no cadastro de áreas contaminadas realizado pela CETESB (FRANZINI 2005). Atualmente, pouco se conhece a respeito dos efeitos da exposição aos HPA, entretanto, existem indícios consistentes que demonstram potenciais efeitos deletérios à saúde, em especial a carcinogenicidade, associados a este grupo de contaminantes.

Como parte dessa mudança de paradigma, pode-se identificar a crescente preocupação por parte dos órgãos e agências de saúde pública em definir limites de exposição ambiental aos agentes químicos de origem antropogênica. Para a definição de tais limites, é necessário o desenvolvimento de modelos exeqüíveis e representativos para avaliar a extensão do dano que estes compostos causam ao ambiente.

Como são muitas as variáveis envolvidas nestes tipos de evento são necessários estudos mais aprofundados, que abordem a questão de forma interdisciplinar para que se possam avaliar os riscos destas exposições. Esta complexidade reflete-se na necessidade de especificidades metodológicas para os estudos nessa área.

Neste contexto, o monitoramento de áreas contaminadas mostra-se necessário para a adoção de medidas de controle, objetivando a prevenção dos danos à saúde do homem e de outros organismos que estejam em contato direto ou indireto com o ambiente contaminado.

Segundo VAN DER OOST et al. (2003), o monitoramento biológico limitava-se, até alguns anos atrás, apenas à quantificação de agentes químicos e/ou seus metabólitos no ar expirado, nos tecidos, secreções e 
excreções biológicas. Essa abordagem era pouco representativa, pois não incluia os efeitos dessas substâncias sobre os organismos expostos.

Quando alterações ambientais causadas por impactos antropogênicos atingem os limites de adequação de espécies menos tolerantes expostas, podem ocorrer perdas de parte desta população por mortalidade. Os efeitos subletais na porção da população mais tolerante, incluindo-se os humanos, apesar de não ocasionar mortalidade direta, trás uma série de impactos de difícil observação. Tais efeitos podem ser estimados pela utilização de metodologias de biomonitoramento, uma vez que a avaliação in vivo pode permitir a obtenção de dados mais completos pela integração de informações referentes à concentração e biodisponibilidade dos contaminantes de forma temporal e espacial (VAN DER OOST et al. 2003).

A situação de estresse causada por um poluente normalmente desencadeia uma cascata de eventos biológicos, podendo cada um destes eventos, em tese, servir como biomarcador (MCCARTHY et al. 1991 citado em VAN DER OOST et al. 2003). O biomarcador é qualquer substância, estrutura ou processo que possa ser medido dentro de um organismo ou em seus produtos, que influencie ou prediga a incidência de efeito deletério ou doença (OMS 2001). Como muitos biomarcadores podem preconizar efeitos em longo prazo, os dados obtidos permitem, a priori, intervenções prévias a efeitos irreversiveis.

Biomarcadores podem ser avaliados após exposição de fontes alimentares, ambientais ou ocupacionais, para elucidar as relações de dose- 
efeito na avaliação de risco, na diagnose clínica e em outras formas de monitoramento (VAN DER OOST et al. 2003).

Segundo a OMS (2001), os biomarcadores são divididos em três categorias: biomarcadores de exposição, que envolvem a deteç̧ão e medição de substância exógena, metabólito ou produto da interação entre o xenobiótico e alguma molécula ou célula alvo de um organismo; biomarcadores de efeito, que incluem a medição de alterações bioquímicas e fisiológicas, que possam ser relacionadas à ocorrência de doença ou prejuízo à saúde e biomarcadores de suscetibilidade, indicativo de uma habilidade inerente ou adquirida de um organismo em responder ao desafio de exposição a um xenobiótico.

Biomarcadores de exposição podem servir para avaliar a integralidade das informações da avaliação de exposição por associar as informações ambientais, as estimativas da dose, os dados epidemiológicos e de atividade humana. Em muitos casos, biomarcadores de exposição podem ser mais confiáveis do que medições externas de exposições, como nas avaliações de eficiência de equipamentos de proteção (OMS 2001). Biomarcadores de efeito podem ser empregados para documentar alterações pré-clínicas e efeitos adversos relacionados a agentes químicos. Biomarcadores de suscetibilidade ajudam a elucidar variações no grau de respostas à exposição, observadas entre diferentes indivíduos (VAN DER OOST et al. 2003). 
A aplicação integrada destas abordagens pode fornecer dados mais fundamentados com relação aos riscos de possiveis impactos à saúde humana provenientes da exposição ambiental a agentes químicos.

Os biomarcadores permitem uma estimativa da dose biologicamente efetiva decorrente da exposição ao composto tóxico, permitindo assim, a avaliação ou ao menos a suspeita de efeitos precoces de agravos à saúde (ambiental ou individual), fundamentando assim algumas estratégias de prevenção e controle a possiveis impactos decorrentes da exposição a xenobióticos (VAN DER OOST et al. 2003).

Os biomarcadores são respostas biológicas que podem relatar a exposição e/ou efeitos tóxicos de agentes químicos dispersos no ambiente, e por isso, podem ser utilizados para avaliar o estado de saúde de organismos expostos e para obtenção de sinais de perigo para avaliações de risco ambiental (PAYNE et al. 1987).

Segundo DEPLEDGE e FOSSI (1994), a avaliação de risco ambiental é definida como "procedimento para identificar quais os prováveis ou atuais efeitos adversos de contaminantes ou de outras atividades antropogénicas no ambiente, sendo estimado o grau de segurança dos seus componentes usando-se para isto, metodologias cientificas".

Muitos compostos químicos e seus metabólitos que contaminam ecossistemas, assim como seus efeitos, necessitam ainda de identificação. O biomarcador é uma ferramenta aplicável a esta finalidade, fornecendo informações para realização de avaliações de risco a estas exposições, podendo ser utilizado para demonstrar efeitos, auxiliar na verificação de 
subgrupos ou indivíduos mais suscetiveis a estes agentes e na identificação de contaminantes presentes, em especial nas situações onde aparecem misturas complexas de variados tipos de agentes quimicos, situação que pode ser exemplificada pela exposição aos HPA.

A ampla distribuição ambiental dos HPA associada a diversas atividades humanas, em especial quanto à matriz energética adotada que tem como principal característica o uso em larga escala de combustiveis fósseis levanta uma série de questões relacionadas à saúde pública em grandes centros urbanos.

Atualmente está bem documentado que os HPA constituem uma classe de compostos, dos quais muitos são potentes carcinógenos para mamíferos, incluindo os humanos. Sua significância como carcinógenos ambientais e ocupacionais tem sido comprovada por uma série de estudos sobre várias fontes ambientais (ex. exaustão veicular e outros processos de combustão), que têm demonstrado que os HPA com mais de três anéis aromáticos são responsáveis por $70-90 \%$ do efeito carcinogênico total relacionado a estas fontes. A formação de HPA devido à combustão incompleta determina sua ampla distribuição ambiental $\mathrm{e}$ as altas concentrações encontradas em alguns locais de trabalho. Assim, devem ser consideradas como um sério perigo à saúde humana (JACOB e SEIDEL 2002).

Apesar de não estarem disponiveis evidências experimentais diretas da carcinogenicidade dos HPA para humanos, vários estudos observacionais indicam uma forte correlação entre a exposição e o aumento 
de incidência de câncer em vários tecidos humanos como pulmão, pele e bexiga urinária. Como resultado desses estudos, o controle regular de HPA em várias situações ocupacionais tornou-se obrigatório (JACOB e SEIDEL 2002).

A investigação da seqüência de eventos iniciados com a exposição a substâncias potencialmente deletérias e que culminam com o aumento dos eventos de morbidade e mortalidade é um dos grandes desafios da pesquisa em saúde pública, e neste contexto, a utilização de biomarcadores é uma das abordagens mais promissoras.

Entretanto, a pesquisa com biomarcadores ainda não alcançou amplamente esses objetivos. Segundo BONASSI et al. (2001), resultados confusos e às vezes conflitantes têm sido obtidos em estudos de populações expostas, assim como os tópicos mais atrativos desta abordagem - a possibilidade de intervenção precoce no desenvolvimento de doenças associadas a agentes químicos e o aumento da capacidade de detecção de exposição a doses reduzidas ou de compostos especificos em uma mistura - têm sido aplicados com sucesso apenas em algumas situações especificas.

O reconhecimento das limitações dos estudos de biomonitoramento tem aumentado a consciência da necessidade de pesquisas que visem à melhoria da validade dos biomarcadores, aumentando sua relevância como metodologia aplicável ao campo de atuação da saúde ambiental, em especial associado à avaliação de riscos. Esta abordagem tem se mostrado cada vez mais necessária, uma vez que a utilização de metodologias 
limitadas pode levar a resultados superestimados ou subestimados, podendo gerar custos e riscos desnecessários. 


\section{OBJETIVOS}

\subsection{OBJETIVO GERAL}

Este trabalho tem como objetivo geral identificar as principais aplicações de biomarcadores para cenários de exposição a hidrocarbonetos policíclicos aromáticos (HPA), visando subsidiar a aplicação desta área de conhecimento em processos de avaliação de risco ambiental, contribuindo para a elaboração de futuras propostas que contemplem questões que não podem ser respondidas através da utilização isolada das metodologias tradicionais, na tentativa de tornar o conhecimento acadêmico formal mais acessivel, diminuindo a distância entre a produção e a aplicação do conhecimento científico.

\subsection{OBJETIVOS ESPECÍFICOS}

- Verificar a situação atual sobre a aplicação de biomarcadores aos processos de avaliação ambiental de risco, com ênfase especial à saúde humana.

- Elaborar um panorama referente aos estudos recentes sobre validação de biomarcadores de HPA, identificando as metodologias já validadas e em processo de validação, suas vantagens e limitações, visando subsidiar sua aplicação à avaliação de risco ambiental.

- Verificar as perspectivas para aplicação futura dos biomarcadores para avaliação de risco ambiental de exposições a HPA. 


\section{MÉTODOS}

Para a realização da presente dissertação, adotou-se como modelo o estudo de atualização. De acordo com o Guia de Apresentação de Teses da FSP/USP (BIBCIR/FSP 2005), os trabalhos classificados como estudo de atualização são aqueles cujo objetivo é reunir seletivamente trabalhos publicados sobre uma especialidade, com vistas à análise e interpretação à luz do progresso do conhecimento da mesma. São, desta forma, trabalhos descritivos e interpretativos baseados na literatura recente sobre a situação global em que se encontra determinado assunto investigativo. Possuem uma estrutura diferente de um trabalho de pesquisa, não incluindo as partes Metodologia, Resultados e Discussão.

O material de estudo foi obtido através de um levantamento bibliográfico na biblioteca de referências eletrônicas (ELECTRONIC REFERENCE LIBRARY - ERL) através da utilização do software WebSPIRS da empresa SilverPlatter Information Database disponibilizado pelo SIBi/USP aos usuários da Universidade de São Paulo e também pelos sistemas de bibliotecas da UNICAMP e UNESP. Este programa está disponivel para acesso a partir de microcomputadores ligados à rede de qualquer uma das instituições mencionadas. Para selecionar as bases de dados mais pertinentes ao assunto da busca, foi realizada uma busca pelo termo livre (biomarker* OR biological marker*) AND (polycyclic aromatic hydrocarbon). Com esta busca foi possível verificar quais as bases de dados contém artigos sobre o assunto em questão. As bases selecionadas foram: 
MEDLINE, BIOLOGICAL ABSTRACTS, ASFA, ZOOLOGICAL RECORDS e CAB ABSTRACTS.

A base de dados MEDLINE, uma das mais completas disponiveis, foi consultada a partir da base de dados PUBMED em sua página de origem devido à maior velocidade de acesso. No sistema de bases de dados PUBMED, foi ainda utilizado o recurso de busca por trabalhos relacionados, sempre que encontrada uma referência pertinente.

Foram selecionados trabalhos que abordam utilização de biomarcadores para avaliação de efeitos de hidrocarbonetos policíclicos aromáticos, com ênfase especial aos trabalhos que apresentam metodologias já validadas e trabalhos que visem à validação de novas metodologias e abordagens. Os demais trabalhos que não se mostraram diretamente relacionados ao tema especificado foram descartados. Para determinação da relevância do trabalho e definição da inclusão ou exclusão do mesmo, foi realizada a leitura dos resumos disponiveis e somente após a seleção das referências pertinentes, foi executada a busca dos trabalhos na integra, os quais foram lidos para realização deste trabalho.

Após a obtenção dos dados, foi executada a fase de análise, que consistiu em agrupar as informações sobre os tipos disponiveis de biomarcadores para HPA e caracterizar a situação dos estudos desenvolvidos até o momento, que subsidiem sua aplicação atual em processos de avaliação de risco ambiental, assim como as perspectivas para aplicação futura. 


\section{HIDROCARBONETOS POLICÍCLICOS AROMÁTICOS (HPA)}

Este grupo de agentes químicos é constituído por compostos orgânicos com dois ou mais anéis aromáticos fundidos formados por átomos de carbono e hidrogênio. Como características gerais, estes compostos possuem baixa solubilidade em água (que tende a decrescer com 0 aumento da massa molecular), baixa pressão de vapor, altos pontos de fusão e ebulição. Estudos de várias fontes ambientalmente relevantes, como os resíduos da combustão de carvão, exaustão veicular, uso de óleos lubrificantes e tabagismo, tem demonstrado que a presença de HPA é o principal responsável pelo potencial carcinogênico dessas fontes. Estes compostos são também utilizados como intermediários na produção de plastificantes (naftaleno), pigmentos (pireno), corantes (antraceno, fluoranteno) e pesticidas (fenantreno). As maiores emissões de HPA são resultantes da combustão incompleta de materiais orgânicos durante processos industriais e outras atividades antropogênicas (OMS 1998), conforme quadros 01 e 02.

Segundo LAW e BISCAYA (1994), a origem antropogênica destes compostos no ambiente está principalmente relacionada à contribuição pirolitica (combustão parcial de combustiveis fósseis), à contribuição petrogênica (derrames de petróleo e derivados) e ao descarte de efluentes domésticos e industriais. Em geral, os HPA de origem petrogênica possuem dois ou três ciclos aromáticos em sua estrutura. No petróleo bruto os 
principais HPA presentes são o antraceno, o fenantreno e o naftaleno e seus derivados alquilados (LAW e BISCAYA 1994).

QUADRO 1: Hidrocarbonetos Policíclicos Aromáticos (HPA) presentes em combustão de madeira e exaustão veicular (diesel e gasolina). ${ }^{a}$

Queima de madeira

Queima de gasolina

(automóveis sem catalisador) $^{b}$

Naftaleno

Fenantreno

Antraceno

Fluoreno

Fluoranteno

Reteno

Pireno

Benzo(b.j.k)fluoreno

Benz(a)antraceno

Benzopirenos
Queima de Diesel

Dimetilfenantreno

Metilfenantreno

Pireno

Benzofluoranteno

Metilfluoranteno

Fenantreno

Criseno

Benz(a)antraceno

Naftaleno

Metilbenzantraceno e Benzopireno

Nota: a. Ordem decrescente aproximada de concentraçăo dos dez HPA mais comuns, entretanto deve-se considerar que a composição e concentraçăo de HPA variam consideravelmente em funçăo da qualidade do combustivel $\theta$ do processo de combustão. b. Catalisadores associados ao sistema de emissőes de automóveis nos modelos mais modernos reduz significantemente as emissóes de HPA.

FONTE: BURCHIEL Q LUSTER (2001)

QUADRO 2: Rotas e fontes de exposição ambiental a Hidrocarbonetos Policíclicos Aromáticos.

Inalação

Queima incompleta de combustiveis fosseis, como derivados de petróleo e carvăo; material particulado com HPA associado proveniente de fontes ocupacionais/industriais; fumaça de incéndios florestais e de tabagismo.

Ingestão Preparo de alimentos com carvăo.

Contato dérmico Exposição a piche ou fuligem.

FONTE: BURCHIEL e LUSTER (2001).

Os HPA de origem pirolítica são caracterizados por apresentarem mais de três ciclos aromáticos e baixo grau de alquilação, quando comparados aos de origem petrogênica (LAW e BISCAYA 1994). Os mais abundantes no ambiente são os benz(a)antraceno, fluoranteno, pireno, criseno, benzofluoranteno, benzopireno, indeno(1,2,3-c,d)pireno e benzo(ghi)perileno, mas existem mais de 100 diferentes tipos de HPA que geralmente são formados como misturas complexas e não como um composto isolado (ATSDR 1995). 


\section{CONTAMINAÇÃO POR HPA}

Além dos resíduos gasosos de combustão, HPA podem ser depositados no solo e também podem alcançar a água intersticial, subterrânea e superficial através de descargas industriais e vazamentos de tanques de armazenamento. Os HPA estão amplamente distribuídos pelo ambiente, onde a exposição pode se dar em ambientes internos e externos. Tipicamente não ocorre a exposição a um único composto, mas a uma mistura de HPA. A exposição pode também ocorrer através de água e alimento contaminados, mas é mais freqüente o contato com vapores ou compostos associados a partículas em suspensão no ar. As principais fontes são tabagismo, exaustão veicular, pavimento asfáltico, processos de combustão de carvão e madeira, queimadas e incêndios florestais, incineração de resíduos e armazenamento de combustiveis. Os niveis basais de alguns HPA representativos no ar variam entre $0,02-1,2 \mathrm{ng} / \mathrm{m}^{3}$ em áreas rurais e 0,15-19,3 ng/m $\mathrm{m}^{3}$ em áreas urbanas ${ }^{1}$ (ATSDR 1995). Em alguns países (ex. Itália e Alemanha), os limites máximos permitidos ou recomendados para benzo[a]pireno variam de 1 a $10 \mathrm{ng} / \mathrm{m}^{3}$. Atualmente, essas concentrações são comumente alcançadas e excedidas no ar de áreas urbanas e rurais habitadas. Concentrações elevadas podem ser esperadas em áreas com intenso tráfego veicular, em túneis rodoviários e em áreas próximas a emissões industriais (JACOB e SEIDEL 2002).

\footnotetext{
${ }^{1}$ Valores basais válidos para os E.U.A. (ATSDR 1995).
} 
O transporte e distribuição de HPA no ambiente são determinados extensamente por propriedades físico-químicas. Em geral, HPA possuem baixa solubilidade em água. Os HPA possuem valores reduzidos para constante de Henry ${ }^{2}$, o que pode determinar a presença de concentrações consideráveis destes contaminantes em ambientes aquáticos, apesar de serem hidrofóbicos e do seu padrão predominante de emissão (via ar atmosférico). Sua afinidade pela fase orgânica é muito maior do que pela fase aquosa, o que determina valores elevados para os coeficientes de partição entre solventes orgânicos e água $\left(\mathrm{K}_{\mathrm{OW}}\right)^{3} \mathrm{e}$ indica uma alta afinidade pela fração orgânica $\left(K_{o C}\right)^{4}$ do sedimento, solo e biota (ATSDR 1995, OMS 1998).

Podem estar presentes no ar como vapor ou adsorvidos a superfície de material particulado, podendo ser carregados a longas distâncias antes de retornarem ao solo através de chuva ou deposição destas partículas. Alguns HPA evaporam da água superficial para atmosfera, mas a maioria se associa a partículas que se depositam no sedimento de corpos aquáticos. Nos solos, é mais comum aparecerem firmemente associados a partículas orgânicas, mas podem contaminar águas subterrâneas e também evaporar alcançando 0 ar. A concentração de HPA na biota pode ser muitas vezes maior do que as concentrações no solo e na água (ATSDR 1995).

\footnotetext{
${ }^{2}$ Coeficiente de partição que expressa a proporção de compostos quimicos entre 0 ar e a água em uma situação de equilíbrio de concentração e é usado como um indicador do potencial de volatilização do composto.

3 O Kow é usado para estimar o potencial de um composto orgânico em se mover da água para o lipídio.

${ }^{4} \mathrm{O} \mathrm{K}_{\mathrm{OC}}$ indica o potencial do composto em se ligar a carbono orgânico, parâmetro relevante para avaliar sua presença no solo e sedimento assim como sua disponibilidade para biota.
} 
A elevada capacidade de metabolização de HPA, em especial pelos organismos de maior complexidade metabólica, é determinante para a não ocorrência de biomagnificação desses compostos. Apesar disso, são contaminantes de interesse quanto ao estudo de efeitos biológicos, uma vez que metabólitos carcinogênicos podem ser formados durante o processo de biodegradação (OMS 1998).

Muitos fatores determinam a possibilidade de ocorrência de efeitos deletérios à saúde, assim como o tipo e a severidade destes efeitos. Estes fatores incluem a dose, duração, rota ou via de exposição, a ocorrência de exposição concomitante a outros compostos (possibilidade de efeito sinérgico) e características individuais como idade, gênero, hábitos de vida, estado de saúde, entre outros (ATSDR 1995).

No ambiente, os HPA são degradados por fotoxidação no ar e água, na presença de radicais como $\mathrm{OH}, \mathrm{NO}_{3}$ e $\mathrm{O}_{3}$, podendo também formar compostos carcinogênicos neste processo (OMS 1998). No ar a degradação pode variar em um periodo de dias a semanas, enquanto no solo e água geralmente varia de semanas a meses, sendo realizada principalmente pela ação de microorganismos (ATSDR 1995).

Apesar destas diversas evidências de degradação, cálculos baseados em parâmetros físico-químicos indicam que HPA com quatro ou mais anéis aromáticos podem ser persistentes no ambiente (OMS 1998).

Outro fator importante na avaliação de exposição e efeito a qualquer agente químico tóxico é o entendimento de sua toxicodinâmica ("o que faz o tóxico ao organismo") e toxicocinética ("o que faz o organismo ao tóxico") 
(PIVETTA et al. 2001), assim como seu destino nos diversos compartimentos ambientais. A quantidade e qualidade destas informações é uma condição determinante para o monitoramento de exposição e efeitos biológicos de agentes químicos.

Como a maioria dos outros xenobióticos lipofilicos, estes compostos são prontamente dissolvidos e transportados através das lipoproteínas das membranas celulares. Em humanos, a principal via de ingresso destes contaminantes é a absorção pelos tratos pulmonar (após inalação destes compostos isolados ou adsorvidos a aerossóis ou particulados), gastrointestinal (após ingestão de comida ou água contaminadas) e por absorção cutânea. A taxa de absorção pelos pulmões depende do tipo de HPA e do tamanho e composição da partícula a qual está adsorvido. HPA adsorvido a substâncias particuladas são absorvidos pelos pulmões mais lentamente do que HPA livre. Modelos animais demonstram que os HPA são amplamente distribuidos por todo o organismo, podendo ser encontrados em qualquer órgão interno, particularmente nos tecidos ricos em lipídios e no trato gastrointestinal, pela reabsorção do produto de excreção hepatobiliar (OMS 1998).

HPA podem ser prejudiciais à saúde em varias circunstâncias. Estudos experimentais com animais demonstraram que alguns HPA, incluindo benzo[a]antraceno, benzo[a]pireno, benzo[b]fluoranteno, benzo[j]fluoranteno, benzo[k]fluoranteno, criseno, dibenzo[a,h]antraceno e indeno[1,2,3-c,d]pireno, causam tumores em exposição por ar contaminado e por contato dérmico. Estudos de exposição alimentar demonstraram 
efeitos reprodutivos, relacionados à fertilidade, problemas gestacionais e alterações congênitas (ATSDR 1995). Dados animais demonstram efeitos deletérios tanto em exposições crônicas quanto agudas (ATSDR 1995). Apesar de não estarem disponíveis dados experimentais com humanos, a contribuição dos HPA para carcinogênese tem sido verificada por uma série de estudos epidemiológicos (JACOB e SEIDEL 2002; GODSCHALK et al. 2003). 


\section{AVALIAÇÃO DE RISCO}

A avaliação de risco é uma área do conhecimento relativamente recente e ainda não devidamente consolidada, seja quanto à fundamentação de conceitos ou quanto à terminologia aplicada. As discussões e reflexões no campo acadêmico ainda estão em fase inicial no Brasil, onde as dificuldades são ampliadas pela falta de precisão na tradução dos termos da literatura internacional.

Um exemplo desta problemática refere-se às confusões entre os termos risk e hazard ou risco e perigo. Estes termos podem ser usados como sinônimos no discurso comum, entretanto, no campo científico são conceitos distintos. Hazard ou perigo é uma propriedade, uma característica qualitativa, enquanto risk ou risco é uma grandeza quantitativa, adimensional e probabilística. A terminologia usada para definir os processos é também controversa. De maneira geral o termo assessment e evaluation são usados como sinônimos, podendo ser traduzidos igualmente como avaliação, existindo uma preferência pelo termo assessment que é o mais citado.

Existem várias definições de risco, mas em geral todas associam risco à probabilidade de ocorrência de um evento indesejável e à magnitude deste dano $(\mathrm{RISCO}=$ probabilidade de exposição $\mathrm{X}$ intensidade do evento adverso) (MOLAK 1996).

A definição de evento adverso ou indesejável é um julgamento de valor. Pode ser definido como morte ou doença de pessoas ou animais; 
como danos ambientais e ecológicos ou até mesmo como prejuizos financeiros. Como aplicação específica ao campo de estudos ambientais, tem-se como objeto definido os danos à saúde. Algumas definições limitam como objeto a saúde humana, outras se referem a componentes ambientais. Entretanto, no contexto de saúde pública, objetivam-se prioritariamente os efeitos à saúde humana.

O conceito de ambiente e o reconhecimento de sua interferência nas condições da saúde humana não são recentes, mas no passado, limitavamse às condições naturais. Com o surgimento da Ecologia, os fatores antrópicos foram introduzidos na visão de ambiente natural, e com isso sua complexidade também foi ampliada. As definições atuais incluem o fator humano ao ambiente, o que demanda que as avaliações de risco enfoquem não apenas os danos à saúde humana, mas também os danos ambientais e ecológicos. Assim, deve-se considerar durante as avaliações de risco à saúde humana também os impactos sobre a saúde de outros organismos, não apenas pela adoção de conceitos preservacionistas, mas considerandose principalmente a sua influência sobre a qualidade de vida e saúde humana, uma vez que os humanos estão necessariamente inseridos no ambiente e por esse motivo não apenas provocam impactos, mas também sofrem os efeitos dessas alterações. Como exemplo, a contaminação difusa em corpos aquáticos, proveniente da agricultura ou outras fontes dispersas pode apresentar uma ameaça considerável a populações humanas em algumas circunstâncias, como a contaminação de fontes e reservas de água para abastecimento público. Neste contexto, a adoção de medidas de 
monitoramento a saúde de outros organismos além dos humanos, pode fornecer informações sobre aspectos gerais quanto ao equilíbrio sistêmico (ecológico) deste ambiente visando à manutenção da qualidade desta água para abastecimento público imediato ou futuro (MOORE et al. 2004), além de fornecer informações necessárias à determinação da capacidade de suporte deste ambiente, necessário à implantação sustentável de futuras atividades antropogênicas potencialmente impactantes.

Algumas vezes o termo ambiental tem sido utilizado para diferenciar ou excluir situações ocupacionais. Em outros momentos, este termo é utilizado para definir cenários não confinados (ambientes outdoor) diferenciando de cenários confinados (ambientes indoor). Esta definição parece ter relação com a definição de campo de atuação de diferentes órgãos e agências que são responsáveis por questões ambientais ou de saúde. Entretanto, do ponto de vista científico/acadêmico, o monitoramento de efeito de contaminantes não se limita a estas divisões artificiais, devendo abranger tanto $o$ ambiente interno quanto $o$ externo ao perímetro industrial, assim como ambientes confinados e não confinados. Desta forma, a avaliação de danos causados por uma fonte, pontual ou dispersa, deve ocorrer de maneira ampla, considerando-se o ambiente como um todo.

Adotando estas definições e conceitos, pode-se definir a saúde ambiental como um objeto de estudo abrangente, que deve considerar a avaliação do status de saúde de toda biota, incluindo populações e comunidades naturais e humanas. 
Desta forma, para os fins desta dissertação, visando evitar possiveis confusões conceituais, quando a citação limitar-se ao objeto saúde humana, adotou-se o termo avaliação de risco à saúde humana e quando se limitar ao objeto saúde de comunidades e/ou populações naturais adotou-se o termo avaliação de risco ecológico. Assim sendo, adotou-se o conceito de avaliação de risco ambiental, definida como um processo amplo, que inclui entre suas abordagens a avaliação de risco a saúde humana e a avaliação de risco ecológico.

Existem muitas propostas quanto ao delineamento de processos de avaliação de risco, mas usualmente, este processo pode ser dividido em duas fases: análise e gerenciamento de risco. Enquanto a análise determina o risco de uma certa situação, o gerenciamento propõe soluções para os problemas identificados (VAN DER OOST et al. 2003). Nos Estados Unidos o gerenciamento é tradicionalmente considerado como uma parte independente que é realizado depois de uma análise de risco (MOLAK 1996). Apesar de distintos, entretanto, ambos devem ser desenvolvidos simultaneamente. Durante o processo de análise de risco, o monitoramento de agentes químicos pode ajudar na determinação da exposição, enquanto o monitoramento biológico pode ser usado para predizer efeitos à saúde e auxiliar a determinação de exposição. Esses procedimentos fornecem informações tanto para elaboração de um laudo de análise quanto para 0 direcionamento dos procedimentos de gerenciamento. 
A primeira consolidação do conhecimento científico sobre a avaliação de risco, foi desenvolvida pela National Academy of Sciences (NAS 1983), que a estruturou em quatro etapas principais: identificação de perigo, avaliação da exposição, avaliação da dose-resposta e caracterização do risco.

\section{- Identificação do Perigo}

Esta etapa tem por objetivo a identificação de todos os agentes químicos de interesse e o levantamento das informaçōes existentes sobre os efeitos destas substâncias à saúde humana, por meio da consulta a banco de dados toxicológicos e à literatura científica especializada (NAS 1983).

Neste primeiro passo da avaliação de risco, busca-se determinar se a exposição ao agente em questão pode causar alterações à saúde. Para estabelecimento de possivel causalidade entre a exposição e o efeito, são fatores determinantes: a natureza do efeito e a consistência do peso de evidências (NAS 1983).

A caracterização destes determinantes considera dados obtidos em estudos epidemiológicos e experimentais (in vivo e in vitro) e a similaridade molecular entre o composto avaliado e outros de efeito reconhecido (NAS 1983).

\section{- Avaliação da Exposição}

O objetivo desta etapa é a determinação da dose recebida pelos individuos expostos. Esta avaliação é baseada na caracterização da magnitude, freqüência, duração e rotas de exposição, que pode ser medida diretamente, por meio de bioensaios ou estimada a partir de modelos 
matemáticos específicos. Ambas as medições apresentam limitações, pois enquanto os modelos matemáticos carregam incertezas importantes, a medida direta da concentração de uma substância em fluídos corpóreos ou órgãos, dificilmente permite que as doses interna e efetiva possam ser estimadas com precisão (NAS 1983).

\section{- Avaliação da Dose-Resposta}

Diferentes agentes possuem capacidades distintas para induzir doenças e o principal aspecto no entendimento deste potencial é o conhecimento sobre como a relação dose-resposta está ligada ao efeito adverso. Esta avaliação é feita por meio das chamadas curvas doseresposta, entretanto esta abordagem envolve extrapolações de efeitos entre doses e/ou interespécies. Estas extrapolações envolvem incertezas estatísticas e biológicas muitas vezes de difícil previsão (NAS 1983).

\section{- Caracterização do Risco}

É a consideração da magnitude da incidência de efeitos sobre a saúde. Este processo é realizado pela combinação das informações obtidas em todas as etapas. Para os efeitos carcinogênicos, o risco é estimado por meio do produto da dose recebida pelos chamados fatores de carcinogenicidade, derivados das curvas dose-resposta. Para efeitos sistêmicos, os quais são funções da dose recebida, o risco é estimado por meio da comparação dos valores de dose estimados com valores de referência adequados. Esta combinação de dados permite a identificação do(s) agente(s) prioritário(s) para controle, fornecendo uma estimativa 
fundamentada sobre os riscos existentes e estabelecendo a base para ações regulatórias (NAS 1983).

Posteriormente, apesar de mantida a estrutura geral, estas definições sofreram algumas modificaç̃es e inclusões, como exemplo, a proposta de VAN LEEUWEN e HERMENS (1995) para implementação de um processo de avaliação de risco ambiental, que conta com as etapas: identificação do perigo, avaliação de efeitos, avaliação de exposição, caracterização de risco, classificação de risco, analise de risco-benefício, redução de riscos e monitoramento.

- Identificação de perigo é a identificação qualitativa dos efeitos adversos que podem ser causados por poluentes;

- Avaliação de efeitos é a estimativa da relação entre a dose ou faixa de exposição ao poluente e a incidência e severidade dos efeitos. A maioria dos estudos é direcionada à determinação da faixa NEL ou NOEL (no effect level) onde não são observados efeitos, que pode ser convertida, para extrapolação a outras espécies, para a faixa PNEL (predicted no effect level) estimativa da faixa onde não são observados efeitos ou ainda PNEC (predicted no effect concentration) estimativa da concentração onde não são observados efeitos;

- Avaliação de exposição é a estimativa de concentrações ou doses para populações ou compartimentos ambientais que estão ou podem estar expostos à contaminação. A avaliação do estado atual de exposição a agentes químicos pode ser feita por medição de concentrações. Pode-se ainda, realizar a estimativa do período de tempo para que sejam observados 
efeitos de concentrações de novos agentes químicos advindos de exposições futuras, ou PEC (predicted environmental concentration);

- Caracterização de risco é a integração dos três primeiros passos do processo da avaliação de risco para que se possa estimar a incidência e a severidade de efeitos deletérios de fácil ocorrência devido à exposição atual ou prevista ao poluente. Pode-se determinar a razão entre PEC/PNEC (o quociente de risco) que combinado a fatores variáveis, liga a análise de risco ao gerenciamento de risco pela quantificação dos perigos e riscos para situações especificas;

- Classificação de risco é a avaliação dos riscos para que se possa determinar se a redução de risco é necessária. Geralmente, a classificação de risco é realizada usando-se dois níveis de risco, onde o limite superior, ou MPL (maximum permissible leven), é o nível máximo permitido e o limite inferior, ou NL (negligible leve/), é o nível negligenciável.

- Análise de risco-benefício é a avaliação dos riscos e benefícios das ações propostas.

- Redução de riscos é a tomada de medidas para proteção humana e/ou ambiental contra os riscos identificados. A redução de riscos pode ser alcançada quando definidos os padrões de segurança.

- Monitoramento é a observação repetitiva, no tempo e espaço, para os propósitos definidos, de um ou mais poluentes ou elementos biológicos, seguindo um cronograma pré-determinado, usando-se métodos comparáveis e padronizados. O monitoramento é essencial em muitas das fases do processo de avaliação de risco ambiental. Durante a formulação do 
problema, o monitoramento químico e biológico do ambiente pode indicar desvios do estado normal, o que permite a identificação de problemas. Durante a implementação de ações, auxilia a certificação de que os problemas identificados estão sendo resolvidos ou mitigados.

No passado, os danos ao ambiente tiveram sua identificação amplamente fundamentada retrospectivamente (SUTER 1993; DUBÉ e MUNKITTRICK 2001; MOORE et al. 2004), baseada em respostas a eventos agudos como os grandes desastres ambientais (ex. derrames de petróleo, explosões em indústrias químicas) (MOORE et al. 2004) e em projetos de implantação e/ou operação de atividades isoladas em áreas pontuais em curtos períodos de tempo (SPALING e SMIT 1993). De maneira geral, esses eventos foram avaliados em termos do impacto à saúde humana e de mudanças visíveis que resultaram em perdas de algumas populações ou comunidades naturais. Entretanto, exposições crônicas raramente resultam em uma mudança rápida e catastrófica. O impacto é geralmente gradual, sutil e freqüentemente de dificil distinção das mudanças ambientais naturais (MOORE et al. 2004) e de impactos provenientes de outras fontes. A escala de tempo em que esses eventos ocorrem está em algo da ordem de décadas, o que torna estes estudos ainda mais complicados (MOORE et al. 2004).

Sem dúvida, a abordagem retrospectiva tem ajudado a reduzir os impactos decorrentes de projetos específicos, mas é deficiente na avaliação da sobreposição de efeitos provenientes de diversas fontes. Segundo DUBÉ e MUNKITTRICK (2001), é necessário que se avalie a pré-existência de 
impactos (determinação do estado cumulativo) antes de se aplicar um modelo que determine o risco de algum possível impacto adicional. Estes autores propõem que a estruturação de um plano integrado e efetivo de avaliação ambiental que considere o estado cumulativo do ambiente deve incluir alguns parâmetros e critérios, como: 1) determinação de especificidades locais, 2) determinação da capacidade de suporte do ambiente e 3) identificação dos objetivos ambientais em longo prazo.

Além dos dados retrospectivos, a avaliação de risco ambiental é também baseada em informações derivadas de estudos sobre as características físico-químicas dos compostos e em estudos experimentais de toxicidade. Apesar destes procedimentos apresentarem um baixo custo, não avaliam diretamente a toxicidade subletal ou outros efeitos adversos em organismos expostos a misturas complexas de poluentes em condições altamente flutuantes que prevalecem no ambiente (MOORE et al. 2004).

Avaliação de risco clássica depende de termos quantificáveis (ex. $\mathrm{LD}_{50}, \mathrm{EC}_{50}$, LOEL, LOEC, NOEL, NOEC) ${ }^{*}$. O desafio é sintetizar estes dados toxicológicos em interpretações cientificamente significativas de risco (EASON e O'HALLORAN 2002).

A confiança nesses procedimentos é substancial, levando-se em conta suas limitações e incertezas, provavelmente porque constituem uma abordagem direta que atende aos apelos estabelecidos pelas autoridades

\footnotetext{
- LD50 e LC50, Dose ou concentração letal para 50\% da população teste; ED50 e EC50, Dose ou concentração que produz uma resposta especifica em $50 \%$ da população teste; MATC, concentraçăo máxima aceitável de tóxico; LOEL, menor nivel de efeitos observados ; LOEC, menor concentração com efeitos observáveis ; NOEL, nivel sem efeitos observáveis ; NOEC, concentração sem efeitos observáveis .
} 
reguladoras. Entretanto, a aplicação de julgamentos científicos sólidos e idéias originais são necessários para elaboração de desenhos de estudo direcionados caso a caso, como ocorre na avaliação de segurança de medicamentos, onde estes princípios tem sido enfatizados há muitos anos (EASON e O'HALLORAN 2002). 


\section{BIOMARCADORES E A ANÁLISE DE RISCO}

A principal razão para se utilizar biomarcadores na avaliação de risco é a possibilidade de obtenção de informações mais sensíveis e detalhadas sobre efeitos biológicos (DEPLEDGE e FOSSI 1994).

O uso de biomarcadores nos processos de avaliação de risco permite que importantes questões sejam respondidas quando outros instrumentos de produção de informação, como questionários e determinação de concentrações ambientais, se mostraram insatisfatórios (OMS 2001).

A utilização de uma seqüência coordenada de biomarcadores pode revelar a presença de agentes químicos biologicamente ativos ou formas biologicamente inertes de contaminação (HANDY et al. 2003). Esta triagem de agentes ativos mediante utilização inicial de biomarcadores não específicos pode além de revelar a presença de contaminantes não inicialmente suspeita (HANDY et al. 2003) também restringir e direcionar outras avaliações ambientais como as físico-químicas, reduzindo custos (OMS 2001; HANDY et al. 2003).

Além disso, os biomarcadores podem permitir mais segurança na interpretação de relações de exposição-efeito do que os métodos clássicos, reduzindo o erro da estimativa de exposição por facilitar o entendimento de efeitos em diferentes padrões de exposições, como em baixos níveis de exposição, ou em padrões variáveis ou intermitentes. Em situaçס̃es onde os efeitos de exposições podem estar sobrepostos, os biomarcadores podem apresentar o estado cumulativo total (OMS 2001). 
Segundo a OMS (2001), é necessária muita atenção na escolha da metodologia mais adequada, pois vários biomarcadores podem estar disponiveis para avaliar a mesma substância, assim como o mesmo biomarcador pode apresentar diferentes significados dependendo do horário da coleta. Como exemplo, o padrão da atividade molecular analisada pode sofrer alterações significantes em sua atividade advindo de interferências de atividade do ciclo circadiano do organismo avaliado.

Segundo HANDY et al. (2003), as respostas de biomarcadores muitas vezes possuem uma longa persistência após a exposição a agentes químicos que são facilmente degradados e não são detectáveis por muito tempo, permitindo a identificação de eventos de poluição intermitentes que o monitoramento químico de rotina não detecta. Entretanto, estes autores salientam que biomarcadores podem ser aplicados ou interpretados inapropriadamente quando não considerados alguns principios básicos. Para um biomarcador de exposição, os pressupostos fundamentais que devem ser observados são: 1) a presença de relação de causalidade entre a concentração do contaminante e a resposta do biomarcador e 2) a presença de correlação entre a dose interna em diferentes concentrações ambientais do contaminante (HANDY et al 2003). Quando atendidos estes princípios, o biomarcador de exposição pode demonstrar uma relação entre a concentração do contaminante no ambiente e a resposta da estrutura alvo analisada (célula, tecido, etc.). Para um biomarcador de efeito, o mais relevante é que a alteração seja avaliada sobre uma função essencial ao funcionamento normal de um sistema biológico (HANDY et al. 2003). Um 
biomarcador ideal deve atender a estes pressupostos, para que possa ser um indice sensivel tanto a parâmetros de biodisponibilidade quanto a respostas biológicas (VAN DER OOST et al. 2003), podendo servir tanto como marcador de exposição quanto de efeito.

Como citado acima, biomarcadores de exposição podem assumir uma relação causal entre a concentração de agentes químicos no ambiente e a resposta de células, tecidos alvo ou de todo o organismo. Entretanto, esta afirmação pode induzir a falsa lógica de que o biomarcador de exposição usado isoladamente é uma forma acurada de medir concentrações ambientais de agentes químicos e que os métodos convencionais de análise de concentrações ambientais não são necessários (HANDY et al. 2003).

Para o caso especifico de exposições a HPA, apesar das metodologias de exposição envolvendo o 1-hidroxipireno urinário e adutos de HPA-DNA estarem relativamente bem desenvolvidas, permitindo seu uso como marcadores de exposição, as aferições físico-químicas de concentrações ambientais devem ser realizadas para que se conheça a proporção relativa das diferentes formas de HPA que sempre aparecem nas misturas, condição usual nas exposições ambientais a este grupo de agentes. A caracterização das proporções relativas e verificação das associações e correlações entre essas concentrações e os padrões do biomarcador permitem a diminuição dos esforços de monitoramento físicoquímico pela adoção de monitoramento por biomarcadores. 
Em alguns casos, biomarcadores de exposição podem ser utilizados para aferir a confiabilidade de modelagens matemáticas de exposição a agentes quimicos. Como exemplo, DOR et al. (2003) realizaram um estudo visando identificar entre cinco modelagens de exposição, qual a mais adequada para o cenário estudado, de solo contaminado por HPA. Neste estudo, as estimativas de exposição dos modelos foram contrapostas às estimativas de exposição obtidas a partir do biomarcador de exposição 1hidroxipireno urinário, metabólito do composto parental pireno. Ambas as abordagens (modelagem e biomarcador) apresentam limitações, pois de maneira geral, assim como os modelos matemáticos carregam incertezas importantes, a medida direta da concentração de uma substância em fluídos corpóreos ou órgãos, nem sempre permite que as doses interna e efetiva possam ser estimadas com precisão. Entretanto, especificamente para o marcador 1-hidroxipireno urinário, é possivel sua utilização como marcador de exposição (dose interna), pois sua utilização desde a década de 80 já produziu uma quantidade significativa de dados que permitiram a identificação dos principais fatores de confusão, que mesmo não eliminando todas as incertezas associadas, possibilitam sua utilização com relativa segurança, o que permitiu no estudo acima citado, a verificação de qual das modelagens disponiveis era mais adequada para o cenário de interesse. 


\subsection{VALIDAÇÃO}

O biomarcador deve ser previamente validado antes que possa ser utilizado como um procedimento de avaliação de risco. $O$ processo de validação de um biomarcador é o conjunto dos procedimentos de estudo necessários para que se possa ter segurança quanto à extrapolação dos dados obtidos a condições reais.

Segundo a OMS (2001), a validade refere-se a acurácia do biomarcador; é uma característica complexa que descreve a extensão com que o biomarcador reflete um evento específico (exposição, efeitos, doença e/ou suscetibilidade) em um sistema biológico.

Dependendo do contexto, a validade pode apresentar diferentes interpretações, quanto à abrangência dos estudos e aos objetivos propostos para sua aplicação.

Para a pesquisa experimental, validade refere-se à natureza do biomarcador e às características necessárias ao ensaio para determinação de seus níveis, presença e/ou atividade, como também à sensibilidade do ensaio para deteç̧ão de resposta em uma concentração conhecida e à especificidade para um evento em particular. Nesta abordagem, procurase saber quais fatores exercem influência sobre o ensaio (SCHULTE 1995; OMS 2001).

Os estudos epidemiológicos dispõem dos dados experimentais de validade como base para estudos em populações humanas, mas para sua realização adequada é também necessário examinar outras questões como 
a exeqüibilidade para uso em humanos, a sensibilidade e especificidade para diferentes populações, assim como a confiabilidade do ensaio em condições de campo. Para isso, é preciso que sejam conhecidos os fatores de interferência, como os relacionados à variação do marcador em diferentes subgrupos definidos pela idade, raça, gênero, doenças préexistentes, dieta e outros fatores comportamentais e ambientais. Somente após a validação nos âmbitos experimental e epidemiológico, o biomarcador poderá ser utilizado de forma sistemática nas avaliações de risco à saúde humana (SCHULTE 1995; OMS 2001).

BONASSI et al. (2001) apresentaram uma proposta geral sobre a validação de biomarcadores para avaliação de risco a saúde humana que consiste em três fases interdependentes:

\section{- Desenvolvimento do Biomarcador}

Nesta fase são avaliados parâmetros relativos à execução do ensaio, como estabilidade, confiabilidade, sensibilidade e especificidade, além dos procedimentos adequados para realização da coleta e preservação de amostras.

A estabilidade, entendida como a capacidade de permanência do marcador no meio biológico amostrado, é às vezes a propriedade mais importante para que o biomarcador seja apropriado para uso em campo. Para avaliação de exposição, a concentração do agente químico parental em um meio biológico é preferível aos seus metabólitos, desde que as estratégias de amostragem e os procedimentos de armazenamento sejam cuidadosamente planejados (OMS 2001). Entretanto, o composto parental 
tende a possuir uma meia vida curta, geralmente é volátil e muitas vezes não se relaciona diretamente aos efeitos adversos, que ocorrem como conseqüência de sua biotransformação e conseqüente bioativação. Quando são focadas as relações dose-resposta, metabólitos urinários podem ser usados com sucesso como biomarcadores de dose interna, nas avaliações de exposição (OMS 2001).

A confiabilidade refere-se à aferição da concordância dos dados, ou seja, a estabilidade das respostas durante a reprodução de um teste nas mesmas condições. Esse parâmetro é importante para avaliar a qualidade das informações, dando suporte à veracidade dos dados para tomada de decisões em politicas públicas e em programas de atenção à saúde. No estudo de confiabilidade está em foco a variabilidade dos dados, inerente ao instrumento e ao avaliador. Denomina-se confiabilidade intraobservador ou teste-reteste, quando um avaliador aplica o teste em dada população, sob as mesmas condições em momentos diferentes; e confiabilidade interobservador, quando dois ou mais avaliadores aplicam o teste numa mesma população, sob as mesmas condições (JEKEL et al.1999; SZKLO e NIETO 2000). Em contraste com os contaminantes do ar, que têm sido foco de vários estudos, poucos estudos foram realizados para avaliar as fontes de variabilidade inter $e$ intra-especificos em medições biológicas de outras formas de exposição. Esta carência de informações sobre o grau de variação de níveis biológicos de contaminantes ou seus metabólicos ao longo do tempo e sobre a variação entre diferentes indivíduos, limita o potencial de comparações (SYMANSKI e GREESON 2002). 
Sensibilidade é definida como a probabilidade de obter-se resultado positivo (doença ou desfecho de interesse) dado que o sujeito é verdadeiramente doente e um resultado negativo quando não-doente (SCHULTE 1995; OMS 2001).

Especificidade refere-se à capacidade do teste em fornecer um resultado seguramente relacionado a uma única fonte de impacto. Em um ensaio de alta sensibilidade, o efeito deve estar relacionado apenas ao agente químico, possibilitando a avaliação da existência de indícios de causalidade entre exposição e efeito observado. Em testes de baixa especificidade, muitos agentes podem causar o efeito observado, o que dificulta a identificação da fonte do impacto, mas pode permitir uma triagem inicial para seleção dos grupos de agentes de interesse, para posterior realização de testes mais específicos.

\section{- Caracterização do Biomarcador}

A fase de caracterização do biomarcador examina sua variabilidade em subgrupos da população e mede o impacto de potenciais fatores de confusão, na associação entre o biomarcador e o evento biológico. Fatores que confundem ou modificam a associação entre o biomarcador e o evento biológico, como idade, sexo e raça, assim como outros fatores bióticos e abióticos, podem estar fortemente correlacionadas tanto à frequêencia de atividade do biomarcador quanto à incidência de muitas doenças, podendo interferir com a habilidade do biomarcador em predizer doenças (BONASSI et al. 2001). 
Nesta fase de estudos, também podem ser realizados estudos transversais para avaliação de prevalência ou estudos ecológicos para avaliação de efeitos populacionais. Com estes estudos observacionais, procura-se a obtenção de dados que permitam a busca de associações entre a variação dos biomarcadores e a variação de incidência e prevalência de enfermidades em indivíduos de populações expostas a contaminantes ambientais, objetivando-se o reconhecimento de indícios de relações de causalidade.

$\mathrm{Na}$ identificação de exposição, o agente químico parental é certamente mais especifico do que qualquer de seus metabólitos, que podem ser derivados de múltiplas fontes, algumas vezes inserindo vários fatores de confusão. Muitas vezes, métodos analíticos estão disponiveis para quantificar tanto xenobióticos orgânicos quanto inorgânicos em alcance nanomolar. A esses niveis, é fácil a interferência devida a fatores de confusão se possiveis contribuições de outras fontes, como hábito de tabagismo, não forem considerados. Também, valores locais de referência precisam ser definidos e atualizados, quando grandes variações espaciais e temporais ocorrem como conseqüência de padrões variáveis de poluição ambiental (OMS 2001). Nesta fase, são construídos bancos de dados referenciais para que, posteriormente, seja possivel a utilização destes biomarcadores, levando-se em conta as especificidades do cenário de estudo. 


\section{- Estudos Longitudinais}

No processo de validação de biomarcadores, como indicadores precoces de agravos à saúde humana, é necessário que se avalie a relação entre a freqüência do biomarcador e a incidência de doenças, baseando-se em estudos observacionais, adotando-se como "Gold Standard" os estudos longitudinais do tipo coorte prospectivo (BONASSI et al. 2001).

O desenvolvimento de biomarcadores para avaliação de risco a saúde humana é mais facilmente obtido quando dados de estudos observacionais envolvendo humanos são ligados a estudos experimentais com animais e linhagens celulares in vitro (OMS 2001).

Biomarcadores podem servir como um elemento comum nos estudos entre diferentes espécies, possibilitando extrapolações neste âmbito. Uma alteração em biomarcadores de animais expostos em laboratório ou em linhagens celulares pode indicar possiveis alterações em humanos expostos em situações ambientais similares (OMS 2001). 


\subsection{ESTUDOS EXPERIMENTAIS, MODELOS ANIMAIS E EXTRAPOLAÇÕES ENTRE ESPÉCIES}

Modelos animais oferecem várias vantagens para avaliação de toxicidade de agentes químicos. DEPLEDGE e FOSSI (1994) sugerem o uso de testes de toxicidade com animais para tentar ligar as respostas dos biomarcadores aos efeitos biológicos (como reprodução e sobrevivência), para fundamentar seu uso na avaliação de risco ecológico. SEXTON et al. (1995), citados em OMS (2001), sugerem a aplicação de biomarcadores para reduzir as incertezas da extrapolação entre doses elevadas e reduzidas ou entre espécies diferentes por prover informações sobre mecanismos comuns, fundamentando a extrapolação de dados de modelos animais para avaliação de risco à saúde humana.

Entretanto, o monitoramento biológico por meio de bioensaios possui várias limitações. A maioria dos bioensaios não leva em conta efeitos devidos às especificidades de cada ambiente, como as interações do agente químico com o sedimento, possível ocorrência de biomagnificação e mecanismos de ação tóxica que não são facilmente medidos em exposições agudas (MCCARTHY et al. 1991 citado em VAN DER OOST et al. 2003).

Assim, dados fornecidos por bioensaios podem apresentar dificuldades de extrapolação para predições de efeitos in situ e por isso, apesar da reconhecida aplicabilidade de bioensaios com modelos animais é necessário rigor quanto aos critérios de escolha e quanto às condições especificas para sua utilização. 
Tradicionalmente, são utilizados modelos animais desenvolvidos para roedores, em praticamente todas as áreas da pesquisa biológica, tanto pela sua facilidade de manejo quanto pela aceitação geral da possibilidade de algumas extrapolações a humanos. Esta familiaridade com modelos de roedores, algumas vezes tem gerado hesitação em se aceitar modelos desenvolvidos para não mamiferos (BALLAROTI e VILLALOBOS 2002), apesar das vantagens que estes apresentam sobre os modelos tradicionais. Muitos destes organismos (ex. peixes e crustáceos, entre outros) produzem uma prole extremamente numerosa em intervalos de tempo reduzidos, possibilitando uma manutenção mais econômica. Possuem ciclos de vida curtos e mais estereotipados. Sua habilidade de maturação sexual em períodos de tempo reduzidos permite uma análise experimental mais detalhada e maior significância estatística (BALLAROTI e VILLALOBOS 2002).

Entre os métodos para extrapolação de dados entre espécies, destaca-se a abordagem tipo paralelogramo. Esta abordagem pode ser usada para avaliar a relação entre biomarcadores e riscos nos grupos expostos (SOBELS 1993 e SUTTER 1995 citados em OMS 2001).

Esta abordagem é derivada dos trabalhos de SOBELS (1993) sobre a extrapolação para humanos de danos genéticos observados em animais. Danos genéticos que não podem ser medidos diretamente, como em linhagens de células germinativas humanas, podem ser estimados pela medição do mesmo tipo de alteração tanto em células germinativas quanto em células somáticas de camundongo (OMS 2001) (figura 1). 
Figura 1: Abordagem tipo paralelogramo para extrapolação de dados entre animais e humanos.

\section{DADOS ANIMAIS USADOS PARA AVALIAÇÃO DE RISCO A SAÚDE HUMANA}

\section{Abordagem em paralelogramo}

Biomarcador animal<smiles>C1=CCCCCC1</smiles>

Biomarcador humano

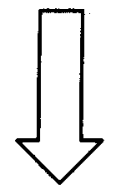

Efeito a saúde animal

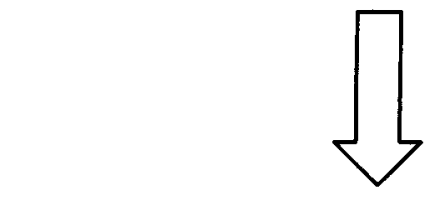

Efeito a saúde humana

\section{Experimentação animal}
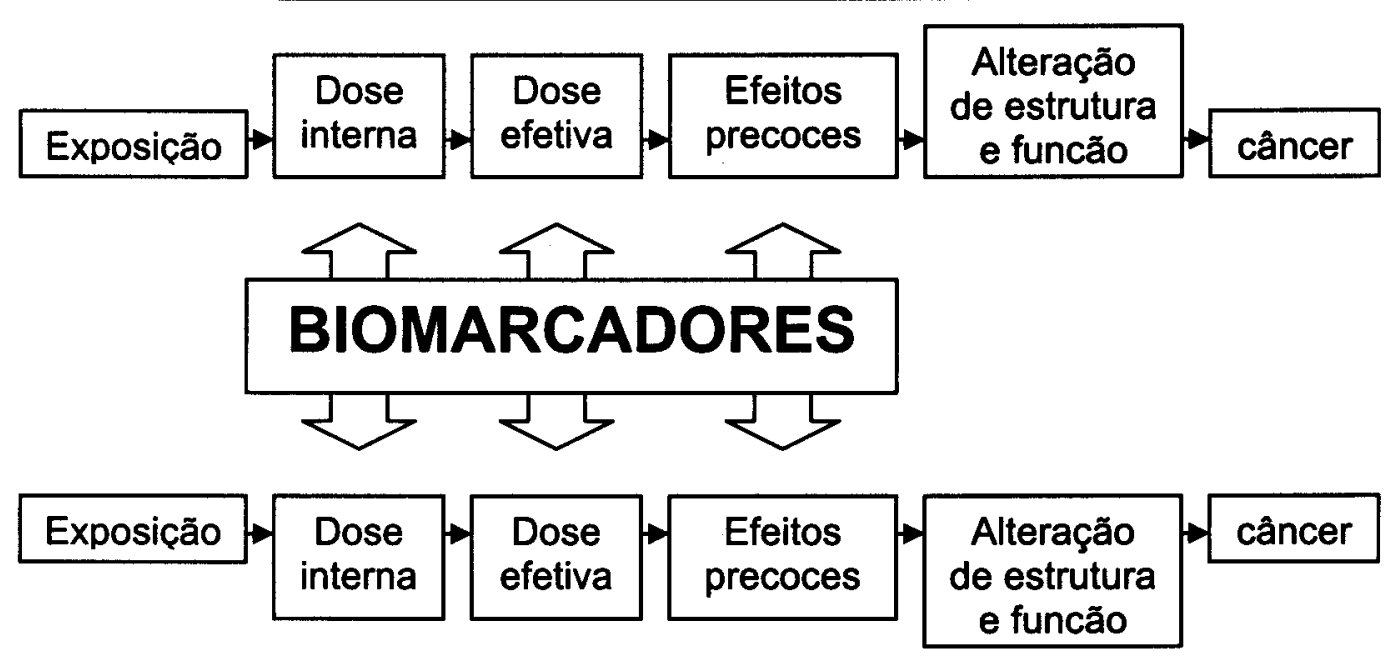

\section{Observação em humanos}

FONTE: ALBERTINI (2001) 
De posse dos dados sobre indução de mutaçס̃es ou aberrações cromossômicas em linhagens germinativas e somáticas de camundongos, é possivel estimar a freqüência de mutações em células germinativas de humanos com base no que se pode medir em humanos (dano genético em linhagens somáticas) (OMS 2001).

A abordagem em paralelogramo original tem sido usada para determinação de efeitos genotóxicos de vários compostos, como exemplo o 1,3 butadieno. Para este agente químico, as estimativas propostas para danos herdáveis em humanos foram baseadas em dados de translocações herdáveis em linhagens germinativas, micronúcleo em medula óssea de camundongo e aberrações cromossômicas em linfócitos de humanos expostos (PACCHIEROTTI et al. 1998).

Outros compostos têm sido caracterizados por esta abordagem, como óxido de etileno, ciclosfofamida e acrilamida (WATERS e NOLAN 1995), fundamentando o estabelecimento de limites de exposição nos guidelines adotados em estudos de avaliação de risco à saúde humana.

SUTTER (1995), citado em OMS (2001), modificou esta abordagem incluindo extrapolações in vitro - in vivo. Nesta abordagem, dados in vitro são usados para testar hipóteses da existência de mecanismos de ação comuns a roedores e humanos (figura 2). 
Figura 2: Abordagem tipo paralelogramo para extrapolação de dados entre modelos animais, cultivo celular e efeitos em humanos.

\section{EXTRAPOLAÇÕES DE EXPERIMENTAÇÃO ANIMAL E CULTIVO CELULAR PARA HUMANOS}

\section{Abordagem em paralelogramo}

animal

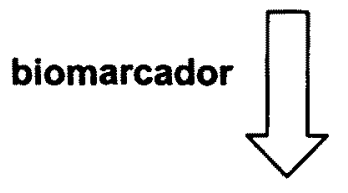

Células animais in vitro
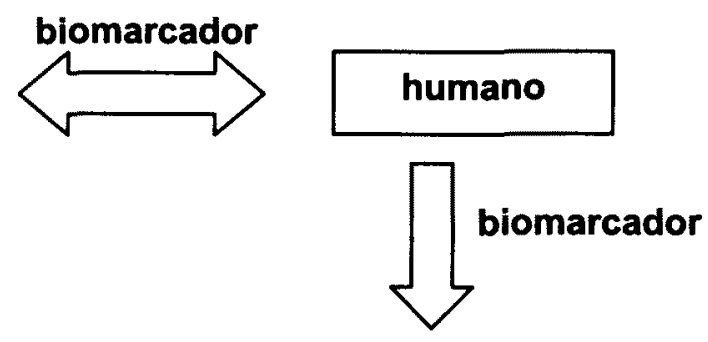

Células humanas in vitro

FONTE: AARDENA e MACGREGOR (2002) 


\subsection{AVALIAÇÃO DE EXPOSIÇÃO E EFEITO DE CONTAMINAÇÃO POR HPA}

Grande parte do conhecimento acumulado sobre a etiologia de doenças não transmissiveis e sua prevenção pode ser creditada ao aprimoramento dos estudos epidemiológicos para avaliar a exposição de grupos populacionais a fatores de riscos ambientais. Após a identificação de muitos fatores ambientais expressivos relacionados a riscos de doenças, os epidemiologistas enfrentam atualmente dificuldades quanto à interpretação dos fatores ambientais tênues, cuja contribuição no incremento de risco é mais dificilmente identificada (WÜNSCH FILHO e GATTÁS 2001).

Entre os fatores ambientais de difícil interpretação, destaca-se a deteç̧ão de um número crescente de agentes quimicos em concentrações reduzidas, graças aos avanços das técnicas analíticas que continuamente têm aumentado em sensibilidade. A identificação de um número elevado de agentes quimicos em concentrações muito reduzidas tem dificultado o estabelecimento de correlação entre estas exposições reduzidas e efeitos, muitas vezes impossibilitando a identificação do agente causal das alterações observadas em estudos epidemiológicos tradicionais (BRANDT e WATSON 2003).

Até pouco tempo, a detecção e identificação de carcinógenos humanos eram baseadas exclusivamente na análise de incidência de tumores em humanos em estudos epidemiológicos. Entretanto, apenas em situações especificas de grandes exposições a HPA, estes métodos têm 
identificado o agente causal. Por causa da longa latência para o desenvolvimento de câncer em humanos, da natureza retrospectiva da epidemiologia e da ocorrência de exposições a concentrações reduzidas de vários HPA, métodos alternativos são necessários para que seja possivel a realização de estudos de avaliação de risco de exposições a HPA (BRANDT e WATSON 2003).

Os HPA são identificados como causa de muitas doenças, em vários sistemas biológicos, entretanto fortes correlações tem sido encontradas entre exposições e ocorrência de carcinogênese (BURCHIEL e LUSTER 2001). Vários autores ${ }^{5}$ têm ressaltado a importância dos HPA na indução de carcinogênese.

Recentemente, a biologia e a genética molecular, assim como novas técnicas laboratoriais, vêm se integrando aos métodos epidemiológicos, auxiliando a formulação e verificação de hipóteses etiológicas (WÜNSCH FILHO e GATTÁS 2001; BRANDT e WATSON 2003). A extraordinária sensibilidade que muitos biomarcadores possuem permite deteç̧ões e medições em concentrações reduzidas, o que pode ampliar o alcance de caracterizações de dose-resposta para avaliação de efeitos subletais (EHRENBERG et al. 1996; OMS 2001). O fator chave em processos de avaliação de risco é a determinação da dose (exposição, interna e efetiva) e sua comparação com a curva dose-resposta.

A determinação de curva dose-resposta, que estabelece a probabilidade ou o grau de resposta que pode ser esperado de diferentes

\footnotetext{
${ }^{5}$ Ver revisão de JACOB e SEIDEL 2002.
} 
niveis de exposição (OMS 2001), também é um passo necessário para determinação de limites de exposição. Parâmetros como incorporação diária aceitável (acceptable daily intake), guidelines ambientais e limites de exposição ocupacional são em sua maioria extrapolados de curvas doseresposta, obtidas em estudos experimentais com modelos animais (OMS 2001). Nestes estudos, o biomarcador de dose interna pode ser usado para diminuir as incertezas das extrapolações (SILBERGELD 1993 ; OMS 2001).

Estudos epidemiológicos fundamentam-se cada vez mais em biomarcadores, como medições indiretas de ocorrência de alterações em um sistema biológico em conseqüência da exposição a poluentes ambientais, fornecendo dados mais confiáveis para aplicação em processos de avaliação de riscos à saúde humana.

A exposição humana a compostos policíclicos aromáticos (CPA), incluindo os HPA, pode ocorrer através de várias rotas, como inalação, absorção cutânea e ingestão. Em geral, as exposições são proporcionais às concentrações dos HPA no ambiente (BRANDT e WATSON 2003), entretanto, o padrão de concentrações de diferentes HPA em uma mistura pode apresentar uma alta variação em diferentes fontes de emissão, podendo também apresentar uma variação temporal na mesma fonte. Por isso, generalizações sobre taxas de exposição e sobre a composição relativa de misturas de HPA não devem ser adotadas (JACOB e SEIDEL 2002), sendo necessários estudos de caracterização para cada situação estudada. 
Apesar da exposição humana ocorrer a misturas destes compostos, para monitoramento apenas um, geralmente benzo[a]pireno, ou um pequeno grupo de oito HPA (benz[a]antraceno, criseno, benzo[b]fluoranteno, benzo[k]fluoranteno, benzo[a]pireno, dibenzo[ah]antraceno, benzo[ghi]perileno e indeno[1,2,3-cd]pireno) são usados para representar a totalidade de CPA. Este grupo de HPA pode ser usado como marcador para o montante de CPA, porque geralmente as concentrações dos compostos totais apresentam proporcionalidade às concentrações dos HPA presentes no ambiente (HEINRICH et al 1994; BRANDT e WATSON 2003).

Após o ingresso do agente químico no organismo, existem muitas possibilidades para sua detecção. A primeira possibilidade é procurar por compostos não modificados (parentais) ou seus metabólitos na urina, sangue, fezes, entre outros. Para biomonitoramento em humanos, são usados principalmente urina e sangue (OMS 2001; BRANDT e WATSON 2003), pela sua facilidade de obtenção.

O metabolismo dos HPA em formas mais solúveis é um passo necessário para sua excreção. Em geral, o composto parental é oxidado pelas enzimas de fase I, produzindo metabólitos primários, e secundários. A principal reação desta fase é a hidroxilação catalisada pelas enzimas monooxigenases, também chamadas de citocromos P450. Além destas, podem ainda ocorrer reações de hidrólise e redução. Estes metabólitos de fase I são conjugados com a glutationa, sulfatos ou ácido glucurônico para formar metabólitos de fase II, com o objetivo de formar compostos mais polares e solúveis em água do que os compostos originais, visando facilitar 
sua excreção. Os metabólitos e conjugados são excretados via urina e fezes, mas conjugados excretados na bile podem ser reabsorvidos no intestino (OMS 1998; JACOB e SEIDEL 2002; BRANDT e WATSON 2003).

A maior parte destas reações resulta em detoxificação, mas podem ser produzidos compostos altamente reativos, como os metabólitos eletrofilicos de HPA. Estes metabólitos podem formar interações covalentes com proteinas e ácidos nucléicos, formando os adutos (OMS 1998; JACOB e SEIDEL 2002; BRANDT e WATSON 2003) que podem alterar o funcionamento normal da célula, desencadeando uma série de efeitos deletérios.

Se adutos de DNA não forem reparados antes da replicação, uma mutação permanente pode se estabelecer. Este tipo de interação é mais estudado do que a interação com proteínas pela possibilidade de ocorrência de alteração na atividade dos ácidos nucléicos, o que pode ser mais facilmente ligado à ocorrência de doenças, como o câncer. As interações covalentes entre estes compostos e proteinas podem aumentar seu tempo de retenção além de alterar a atividade da proteina ligante (OMS 1998; JACOB e SEIDEL 2002; BRANDT e WATSON 2003).

A fração de HPA excretados sem modificação (compostos parentais) é muito menor do que a fração de metabólitos hidroxilados. Estes compostos, formados durante a fase I do metabolismo de xenobióticos, são excretados na urina principalmente como compostos conjugados. Os metabólitos hidroxilados podem ser utilizados como biomarcadores, pela sua capacidade de indicar a dose interna recebida (JACOB e SEIDEL 2002). 


\subsubsection{METABÓLITOS HIDROXILADOS DE HPA -}

\section{BIOMARCADORES DE DOSE INTERNA}

O metabólito hidroxilado mais comumente utilizado em exposiçōes a HPA é o 1-hidroxipireno, mas outros metabólitos também podem ser monitorados, como metabólitos do benz[a]antraceno, 3hidroxibenzo[a]pireno e fenantreno, que segundo JACOB e SEIDEL (2002) podem apresentar, em algumas circunstâncias, vantagens analíticas sobre 0 metabólito 1-hidroxipireno. Para monitoramento de tabagismo, pode-se utilizar a cotinina (metabólito hidroxilado da nicotina) o que permite 0 controle desta variável de interferência em estudos de exposição ambiental a HPA (BRANDT e WATSON 2003).

Os métodos desenvolvidos para medição direta de concentrações de metabólitos específicos de HPA excretados na urina fornecem dados que permitem uma estimativa mais acurada quanto ao ingresso total de HPA, se comparado a medições ambientais, uma vez que essas estimativas de dose interna consideram a exposição total, por várias rotas de ingresso, incluindo absorção cutânea e respiratória (JACOB e SEIDEL 2002).

De acordo com JACOB e SEIDEL (2002), para a eleição do metabólito urinário mais adequado a cada situação analisada, deve-se considerar entre os HPA presentes, o constituinte mais comum a todas as emissões consideradas. Quando o padrão de HPA apresenta uma grande variação, mais de um metabólito deve ser adotado, visando diminuir os erros 
desta estimativa. Entre os principais compostos presentes nas misturas de HPA, destaca-se o pireno, presente na maioria das emissões de HPA.

O 1-hidroxipireno é o principal metabólito do pireno formado em mamíferos (BOYLAND e SIMS 1994 citados em JACOB e SEIDEL 2002; JONGENEELEN 1997; SORENSEN et al. 2003). O 1-hidroxipireno urinário é um biomarcador de exposição sensível, pois apresenta correlações significantes com as exposições a HPA, constituindo um método analítico robusto (LEVIN 1995 citado em OMS 2001). Recentemente, muitos autores têm repetidamente concordado com essas afirmações ${ }^{6}$, indicando o 1hidroxipireno urinário como o parâmetro mais relevante nas estimativas de exposição individual a HPA.

Em estudos de monitoramento humano, tem sido descrito que a meia-vida de 1-hidroxipireno na urina pode variar entre 4-48h (BRANDT e WATSON 2003). Esses dados sugerem que o tempo entre a exposição e o recolhimento de amostras de urina é um fator importante que pode ser uma fonte de incertezas. A abordagem mais utilizada para exposições ocupacionais é a coleta no término do período de trabalho. Para exposições ambientais, coletas a cada $24 \mathrm{~h}$ demonstram a melhor correlação com as concentrações externas (JONGENEELEN 2001; BRANDT e WATSON 2003).

Segundo JONGENEELEN (2001) para avaliação de exposições ambientais deve-se estabelecer os valores basais de 1-hidroxipireno para cada população avaliada, uma vez que o valor basal para excreção de 1-

\footnotetext{
${ }^{6}$ Jongeneelen 2001; Viau et al. 2004; Tsai et al. 2004; Siwinska et al. 2004; Hansen et al. 2004.
} 
hidroxipireno pode variar consideravelmente. Neste mesmo estudo, os autores estabeleceram um guideline com valores referenciais de concentrações de 1-hidroxipireno para algumas exposições ocupacionais, visto que nestes cenários, existe pouca variação do padrão de exposição, onde as proporções das diferentes formas de HPA permanecem relativamente constantes. Entretanto, para exposições ambientais, onde as concentrações podem variar muito, é necessária a caracterização do padrão de exposição para cada situação analisada (JONGENEELEN 2001).

\subsubsection{ADUTOS DE DNA-HPA - BIOMARCADORES DE DOSE}

\section{EFETIVA}

A contribuição dos HPA na indução de carcinogênese humana é indiscutivel. Técnicas epidemiológicas têm sido empregadas para demonstrar a associação entre redução de exposições a HPA e prevenção de câncer. Entretanto, a utilização destas técnicas é restringida pela necessidade de uso obrigatório de um grande número de voluntários e pela necessidade de dados quantitativos de exposição (JACOB e SEIDEL 2002; GODSCHALK et al. 2003).

A indução química de carcinogênese é um processo complexo, com múltiplos estágios que envolvem mutações em genes reguladores do crescimento celular (proto-oncogenes) e em genes supressores de tumor (WÜNSCH FILHO e GATTÁS 2001; BRANDT e WATSON 2003; 
GODSCHALK et al. 2003). O passo inicial é a interação de metabólitos eletrofilicos com o DNA, que podem resultar em uma seqüência modificada de nucleotídeos, levando a modificações na expressão do gene, que podem culminar na disruptura do processo de regulação normal do crescimento celular (HALL e GROVER 1990 citados em GODSCHALK et al. 2003).

A dose interna de HPA pode ser avaliada pela medição de concentrações de seus compostos parentais ou metabólitos eletrofilicos em fluidos corpóreos, entretanto, estas medições não representam necessariamente a dose efetiva. A utilização da epidemiologia molecular fornece uma ampla gama de possíveis biomarcadores que podem ser utilizados em estudos que contemplem exposiçōes a HPA (GODSCHALK et al. 2003).

Para determinação da dose efetiva de compostos carcinogênicos, a medição de adutos de DNA demonstra-se um dos biomarcadores mais promissores, por levar em conta diferenças individuais quanto à exposição, absorção e distribuição de agentes químicos, sua metabolização a formas reativas ao DNA, sua detoxificação em intermediários reativos, assim como a reposição celular e o reparo de danos ao DNA.

Existem várias evidências sobre o papel dos adutos de HPA-DNA na transformação de uma célula normal em uma célula cancerosa, obtidas a partir de experimentos com cultivo celular de exposições in vitro, de estudos com modelos animais, particularmente com roedores e de estudos in vivo, com voluntários humanos sadios (expostos em situações ocupacionais ou ambientais) e pacientes com câncer (GODSCHALK et al. 2003). 
Em uma recente revisão, GODSCHALK et al. (2003) afirmam que considerando os dados in vitro e in vivo disponiveis, existem evidências suficientes para assumir que adutos de DNA estão relacionados a risco de câncer em humanos, e que é possivel sua utilização não apenas para avaliação de exposição, mas também para avaliação de risco de câncer em humanos. Entretanto, para um uso efetivo e exeqüivel de adutos de DNA, vários aspectos precisam ser considerados.

Questões éticas limitam os tipos de tecido disponiveis para análises de adutos de DNA em humanos. A maioria dos órgãos alvo de carcinogênese induzida por HPA não é acessivel em amostragens de rotina. Por isso, adutos de DNA têm sido estudados predominantemente em tecidos substitutos, com células de fácil obtenção, onde o principal exemplo são os leucócitos circulantes (GODSCHALK et al. 2003).

Outra crítica a este modelo é que estas células substitutas não são necessariamente alvos para HPA e nem sempre as mais sensiveis para formação de adutos, o que levanta questionamentos sobre a confiabilidade das estimativas in vivo. Resultados conflitantes com relação à formação de adutos HPA-DNA em leucócitos têm sido encontrados. Alguns estudos de exposição ocupacional (PELUSO et al. 2001; GODSCHALK et al. 2003) demonstram a ocorrência destes adutos também em indivíduos não expostos. Estudos em grupos de fumantes (PHILLIPS et al. 1990; GODSCHALK et al. 2003), não demonstram alterações significativas na formação destes adutos em relação ao grupo controle, sugerindo outra possivel fonte além do tabagismo. Alguns estudos têm demonstrado que a 
exposição dérmica (HERBERT et al. 1990) e a ingestão de HPA (GODSCHALK et al. 2003) podem ser mais significativos do que a inalação para formação de adutos HPA-DNA em leucócitos circulantes.

A possibilidade de múltiplas vias de exposição pode trazer dificuldades na avaliação da correlação entre os niveis de adutos nos tecidos alvos e os niveis observados nas células substitutas. Para a correta interpretação das diferentes contribuições de várias vias de exposição envolvidas em um evento estudado, é necessária a avaliação das diferentes subpopulações de leucócitos. Segundo GODSCHALK et al. (2003), em estudos com humanos a relação entre formação de adutos de DNA em leucócitos e células pulmonares não foi inicialmente observada (PHILLIPS et al. 1990). Entretanto, estudos posteriores (WIENCKE et al. 1995; GODSCHALK et al. 2003) evidenciaram a existência de correlação apenas nas células mononucleares (fração dos leucócitos correspondente aos linfócitos e monócitos), demonstrando que a formação de adutos em fraç⿸̃es celulares de leucócitos podem refletir niveis de adutos em órgãos alvo relevantes, permitindo sua utilização no monitoramento e avaliação de risco de desenvolvimento de câncer.

Os leucócitos podem ser subdivididos em monócitos (5-10\% do total de leucócitos), linfócitos (20-40\%) e granulócitos (40-75\%). O período de permanência dos linfócitos (de dias a anos) pode qualificar estas células para avaliação de exposições em longo prazo. Por outro lado, monócitos e granulócitos possuem uma permanência muito menor (de horas a dias), representando apenas exposições recentes (GODSCHALK et al. 2003). A 
variabilidade no período de permanência dos subtipos de leucócitos faz com que após um período de tempo, os adutos existentes nos leucócitos totais sejam incertos. Qualquer distúrbio imunológico, como um resfriado comum, pode afetar profundamente o número e o tempo de permanência destas células (GODSCHALK et al. 2003).

Outros tipos de tecidos substitutos têm sido usados para avaliar exposição a HPA. DE FLORA et al. (1993) sugerem a utilização de células obtidas por lavagem bronco-alveolar para estudo de exposição a carcinógenos especificamente por inalação, principal rota de exposição humana a HPA. O tipo celular predominante neste modelo são os macrófagos alveolares, originados de monócitos circulantes. A aplicabilidade de tecidos substitutos em estudos de campo é amplamente dependente de sua acessibilidade e assim, as subpopulações de leucócitos circulantes demonstram maiores vantagens sobre os macrófagos alveolares. Entretanto, é possivel a obtenção de macrófagos alveolares através de indução de escarro, técnica de fácil aplicação e relativamente pouco invasiva (BESARATINIA et al. 2000). Os níveis mais elevados de adutos de DNA foram observados, respectivamente, nas células alveolares, nos monócitos mononucleares circulantes e nos granulócitos, o que sugere que as medições de adutos nestas duas primeiras células permitem uma análise mais sensivel para avaliação de exposições por inalação a HPA (GODSCHALK et al. 2003).

O entendimento das relações entre dose-resposta e a persistência de adutos é indispensável para os estudos de monitoramento de exposições 
que usem adutos de DNA como parâmetro, fornecendo informações sobre de que forma e com que velocidade os niveis de adutos podem mudar em resposta a mudanças nos padrões de exposição.

A relação dose-resposta entre a exposição a HPA e a formação de adutos tem sido estudada para avaliar a aplicabilidade de adutos de DNA para distinguir dois ou mais niveis de exposição (GODSCHALK et al. 2003), visando a sua fundamentação como metodologia auxiliar nas estimativas de exposição. Estudos com modelos animais mostram uma forte relação doseresposta em exposições a doses reduzidas, o que nem sempre é encontrado em humanos. Em tecido pulmonar de fumantes, foi encontrada uma correlação entre o nível de adutos e a quantidade de cigarros consumidos por dia, mas a curva dose-resposta das subpopulações de leucócitos tende a nivelar-se em altas doses, de mais de 20 cigarros diários (DALLINGA et al. 1998). De maneira geral, altos níveis de adutos e/ou grandes proporções de indivíduos com niveis de adutos detectáveis são encontrados, mas pode ocorrer saturação em altas doses (GODSCHALK et al. 2003).

O potencial destas células em metabolizar carcinógenos, incluindo os HPA, é bastante descrito pela literatura. Entretanto, indivíduos diferentes expostos a niveis similares de exposição podem apresentar diferenças nos niveis de adutos formados. Estas variações provavelmente estão relacionadas ao polimorfismo genético das enzimas envolvidas na ativação ou detoxificação de HPA (ex. glutationa-s-transferase, citocromo P450) e no mecanismo de reparo do DNA. Esta variação interindividual é responsável 
por diferenças na suscetibilidade ao desenvolvimento de cânceres e vários estudos têm sido direcionados à identificação dos genes responsáveis por tais diferenças (SCHOKET et al. 2001; GODSCHALK et al. 2003; NORPPA 2004). Variações intra e interindividuais também podem ser observadas e estão relacionadas principalmente à intermitência do padrão de exposição, além da ação de outros fatores de interferência, como tabagismo, diferenças no padrão alimentar e diferenças sazonais na biodisponibilidade dos compostos, entre outros. Desta forma, variações intra e interindividuais devem ser caracterizadas antes que os adutos de HPA-DNA possam ser aplicados como marcadores de exposição em estudos de larga escala (SCHULTE e PERERA 1993; GODSCHALK et al. 2003; SCHOKET et al. 2001; NORPPA 2004).

BRANDT e WATSON (2003) citam que, adutos de DNA podem ser determinados por vários métodos, entre os quais o mais sensivel é $0{ }^{32} P$ post-labeling assay, método originalmente desenvolvido por RANDERATH et al. (1981) e usado em associação a técnicas de imunoensaio ${ }^{7}$.

\subsubsection{ALTERAÇÕES CITOGENÉTICAS - BIOMARCADORES DE EFEITO PRECOCE}

Em cultivo celular de linfócitos periféricos, alterações citogenéticas como aberrações cromossômicas, troca de cromátides irmãs e micronúcleo

\footnotetext{
${ }^{7}$ Técnica recentemente revista por Phillips et al. 2000 .
} 
têm sido aplicados por muitos anos como biomarcadores de exposição e efeito precoce em exposições a carcinógenos genotóxicos (ALBERTINI et al. 2000; NORPA 2004).

Permuta entre cromátides irmãs é a troca de produtos de replicação de DNA entre cromátides irmãs em lócus gênicos aparentemente homólogos. O mecanismo de formação de permutas não está bem estabelecido, mas podem ser conseqüência de erros na replicação do DNA (BRANDT e WATSON 2003; NORPPA 2004). Aberrações cromossômicas são anormalidades no número ou estrutura dos cromossomos, visíveis durante a metáfase da divisão celular. São em geral, resultado de quebras cromossômicas ou quebras e rearranjos entre cromossomos diferentes. Por causa de sua forte correlação com câncer, aberrações cromossômicas são vistas como marcadores de risco de câncer (BRANDT e WATSON 2003; NORPPA 2004). Micronúcleos são pequenos corpos nucleares formados por separação do núcleo principal durante a divisão celular. Em geral, contém um fragmento cromossômico ou um cromossomo completo que é separado pelo efeito tóxico sobre as proteinas do fuso envolvidas na separação de cromátides durante a divisão celular (BRANDT e WATSON 2003; NORPPA 2004).

Como a maioria dos biomarcadores de genotoxicidade, alterações citogenéticas em linfócitos são estimativas obtidas em tecidos substitutos, onde se presume que representem alterações cromossômicas mais especificas, importantes na carcinogênese dos tecidos alvo. Evidências têm sido acumuladas de estudos que mostram uma alta freqüência de 
aberrações cromossômicas, mas não de permuta ou micronúcleo em linfócitos periféricos como parâmetros preditivos de incremento de risco de câncer (BONASSI et al. 1995; BRANDT e WATSON 2003; SMERHOVSKY et al. 2001, 2002; NORPPA 2004). A relevância do incremento de freqüência de alterações citogenéticas como biomarcadores de risco de câncer tem sido corroborada por estudos epidemiológicos, que tem sugerido a alta freqüência de aberrações cromossômicas como o melhor parâmetro preditivo para incremento de risco de câncer (BRANDT e WATSON 2003; NORPPA 2004).

Segundo NORPPA (2004), a complexa exposição a HPA tem sido extensivamente investigada em vários cenários ocupacionais e em fumantes. Outros estudos examinam exposições a um único agente químico. Os biomarcadores de exposição mais amplamente utilizados são os adutos de DNA; as técnicas ${ }^{32} P$-postlabelling e imunoensaios são os métodos mais freqüentemente aplicados para sua medição. Biomarcadores de efeito precoce, principalmente parâmetros citogenéticos, são usados para monitoramento de exposições a genotóxicos. Os alelos P4501A1Mspl, P4501A1lle462Val e GSTM1, são os mais freqüentemente incluídos nos estudos de polimorfismo em associação a niveis de biomarcadores de exposição. Nestes estudos, são investigadas as correlações entre carcinógenos/adutos de DNA e 1-hidroxipireno urinário e genótipos das enzimas de fase I e II, envolvida no metabolismo de HPA. 


\subsubsection{POLIMORFISMO GENÉTICO - BIOMARCADORES DE SUSCETIBILIDADE}

Uma atenção crescente tem sido direcionada a polimorfismos genéticos que podem modular a resposta humana em exposições a agentes genotóxicos. O papel do polimorfismo genético na suscetibilidade a genotóxicos específicos pode ser mais facilmente estudado através da utilização de biomarcadores, como as alterações citogenéticas (NORPPA 2004).

Qualquer polimorfismo que altere o metabolismo de xenobióticos ou a resposta celular a danos no DNA pode alterar a suscetibilidade individual a carcinógenos genotóxicos. Estudos de epidemiologia molecular têm sido usados para estudar esta questão (AU et al. 2001; GARTE 2001; NORPPA 2004).

Os estudos de polimorfismo genético dependem do tipo de material biológico examinado, da exposição e da composição étnica da população de estudo. Como os niveis de exposição individual geralmente variam muito, estimativas de exposição confiáveis são cruciais para a correta interpretação da interação genótipo-exposição. Como os marcadores citogenéticos podem representar exposições ocorridas meses antes da amostragem de tecido, simples medições de metabólitos urinários ou de concentrações ambientais podem não ser representativas para o periodo de exposição mais relevante (NORPPA 2004). 
Quando ocorrem diferentes níveis de exposição, devem-se dividir os indivíduos expostos em diferentes categorias. Na maioria dos estudos é necessária uma comparação entre estes grupos e um grupo controle, para que seja possivel a distinção de interações exposição-genótipo de valores basais do biomarcador (NORPPA 2004).

Diferenças genotípicas nos grupos expostos que não são vistas no controle sugerem efeitos genotipicos especificos da exposição. Efeitos vistos tanto em expostos quanto em controles, ou apenas nos controles, provavelmente representam efeitos genotípicos no nivel basal do biomarcador citogenético (NORPPA 2004).

Outro fator importante que determina se o efeito do polimorfismo genético pode ser visto como um biomarcador citogenético é a expressão de diferenças genotípicas na célula ou tecido examinado. Como exemplo, glutationa-s-transferase M1 (GSTM1) e T1 (GSTT1) detoxificam vários agentes químicos reativos e são expressos em leucócitos e eritrócitos (NORPPA 2004). Individuos que possuem pelo menos uma cópia para os alelos GSTM1 A ou GSTM1 B possuem atividade da GSTM1, mas aqueles que são homozigotos para deleção do gene GSTM1 (genótipo GSTM1 nulo) não possuem esta atividade (STRANGE et al. 2000). A freqüência do genótipo GSTM1 nulo é de aproximadamente $50 \%$ na população caucasiana (GARTE et al. 2001). De maneira semelhante, a deleção em homozigose do gene GSTT1 (genótipo GSTT1 nulo), encontrado em 13-28\% dos caucasianos, os torna inábeis para detoxificação mediada por GSTT1 (GARTE et al. 2001; NORPPA 2004). Conseqüentemente, dano citogenético 
induzido por substratos genotóxicos de GSTM1 ou GSTT1 podem ser esperados como sendo elevados nas células do sangue em indivíduos GSTM1 e T1 nulo, que perderam totalmente as respectivas atividades enzimáticas (NORPPA 2004).

KNUDSEN et al. (1999) observaram que motoristas de ônibus (não fumantes) GSTM1 nulo, expostos a poluição aérea urbana, apresentavam uma alta freqüência de aberrações cromossômicas se comparados a motoristas GSTM1 positivos.

Estudos de adutos de DNA têm sugerido que o genótipo GSTM1 nulo predispõe os portadores a efeitos genotóxicos do ar poluído por HPA (BRESCIA et al. 1999; ŠRÁM et al. 1999; NORPPA 2004). ICHIBA et al. (1994) observaram que a freqüência de micronúcleo em linfócitos está correlacionada com o nível de adutos de DNA apenas em indivíduos GSTM1 nulo.

Muitas das enzimas monooxigenases, também chamadas citocromos P450, são polimórficas e alguns genótipos são associados com alta atividade enzimática, sendo que uma alta indução é esperada quando exposta a agentes químicos. Os principais alelos variantes do gene citocromo P450 1A (CYP1A1) incluem os alelos 2A, 2C, 2B e 4 (HUNG et al. 2003). Estudos sobre o efeito do polimorfismo do citocromo P450 sobre danos cromossômicos são restritos, e sua interpretação é complicada pela pouca clareza das associações entre o genótipo de citocromo P450 e a expressão fenotípica dos raros alelos variantes (NORPPA 2004). 
Biomarcadores citogenéticos refletem os efeitos celulares de carcinógenos genotóxicos. Altos níveis de aberrações cromossômicas em linfócitos periféricos têm sido observados para predição do incremento de risco de câncer tanto para tabagismo quanto para exposição ocupacional a carcinógenos.

Vários polimorfismos de enzimas de metabolismo de xenobióticos têm indicado um efeito indutor sobre os biomarcadores citogenéticos. Por exemplo, existem evidências sobre o elevado nivel de alterações citogenéticas em fumantes com o genótipo GSTM1 nulo e um aumento basal da freqüência de aberrações cromossômicas do gene NAT2 "slow acetylators" (genótipo 2 para a enzima de fase II $\mathrm{N}$-acetiltransferase) e aumento da freqüência de permutas e aberrações cromossômicas em individuos GSTT1 nulo (NORPPA 2004).

A importância de vários polimorfismos genéticos na determinação do nivel de alterações citogenéticas depende do parâmetro citogenético, do agente químico e da composição étnica da população de estudo. Biomarcadores citogenéticos podem ser usados para identificar subgrupos sensiveis a carcinógenos. Investigações sobre estes genótipos em estudos de biomarcadores citogenéticos têm como objetivo ajudar no controle da variabilidade individual na detecção de efeitos de exposição (NORPPA 2004). 


\section{APLICAÇÕES RECENTES E PERSPECTIVAS FUTURAS}

As técnicas tradicionais de epidemiologia têm sido empregadas para demonstrar associações entre exposição a substâncias perigosas e desenvolvimento de doenças, como o câncer. A respeito do câncer, os parâmetros para as investigações são usualmente, mortalidade e incidência de doença. Entretanto, essa abordagem tradicional apresenta limitações (BONASSI e AU 2002), como a aplicação dos resultados da investigação a toda a população, visando à implementação de ações de prevenção de doenças, sem a consideração das variações interindividuais. Como muitas dessas variações têm um papel significativo na determinação da suscetibilidade individual, essas variáveis precisam ser incorporadas aos estudos para melhorar sua confiabilidade. Dessa forma, modificações devem ser integradas à abordagem tradicional para aumentar a sensibilidade e especificidade dos estudos epidemiológicos (ALBERTINI 2001; BONASSI et al. 2001; BONASSI e AU 2002).

Entre as abordagens propostas para melhorar os protocolos epidemiológicos, a proposta de PERERA e WEINSTEIN (1982), citado em BONASSI e AU (2002), tem sido uma das mais adotadas. Esses autores sugerem a incorporação de técnicas analíticas laboratoriais aos tradicionais surveys epidemiológicos para elucidar a base bioquímica ou molecular da etiologia das doenças (BONASSI e AU 2002). Muitos estudos têm sido conduzidos de acordo com essa proposta, o que tem propiciado a obtenção de dados analíticos úteis como as doses de exposição interna e efeitos 
biológicos, principalmente por meio das alterações citogenéticas, como medições de adutos de DNA, aberrações cromossômicas e mutações genéticas, entre outras. Assim, surgiu o novo campo da epidemiologia molecular que utiliza biomarcadores como parâmetros (endpoints) biológicos intermediários (BONASSI e AU 2002).

Segundo revisão recente de BONASSI et al. (2005), a avaliação de aberrações cromossômicas (AC) e micronúcleo (MN) como parâmetros intermediários em estudos transversais tem sido realizada para avaliar os efeitos de dano ao DNA, resultantes de uma ampla gama de exposições. Estes estudos podem ser usados para fornecer insights mecanísticos sobre as relações de exposição-doença e para suplementar de maneira sugestiva, porém ainda inconclusiva, evidências de carcinogenicidade de uma exposição. Além disso, esses estudos podem avaliar quando um dano cromossômico está ou não relacionado a novas exposições que não estão presentes tempo suficiente para que seja avaliada sua associação com câncer, através dos estudos epidemiológicos longitudinais.

Entretanto, é necessária precaução para interpretação desses parâmetros. Uma associação positiva entre a exposição e as freqüências de $A C$ e $M N$ pode ser informativa, mas uma associação nula não certifica a ausência de efeito carcinogênico, que pode estar ocorrendo por meio de um mecanismo não relacionado à indução de AC e MN (BONASSI et al. 2005).

A vantagem marcante da aplicação de biomarcadores aos estudos transversais é que informações detalhadas e acuradas podem ser obtidas a 
respeito dos padrões atuais de exposição, dos possiveis fatores de confusão (confounders) e dos efeitos específicos (BONASSI et al. 2005).

Como as freqüências de $\mathrm{AC}$ e $\mathrm{MN}$ não são fixas, mas mudam de acordo com o padrão de exposição e outros fatores como a idade (ALBERTINI et al. 2000), a informação obtida pode evidenciar uma relação temporal relevante (BONASSI et al. 2005). A pouca estabilidade das AC e MN determina sua permanência por meses, enquanto que as translocações podem permanecer estáveis por vários anos (TUCKER 2002). Com estudos transversais é possível o processamento de amostras para análise de $\mathrm{AC}$ e $\mathrm{MN}$ em um período relativamente curto de tempo após a coleta, aumentando a viabilidade celular e diminuindo, deste modo, a probabilidade de erros de medição. Entretanto, o processamento de amostras de sangue para análise de $A C$ e $M N$ é laborioso e a avaliação simultânea de um grande número de amostras pode ser problemática (BONASSI et al. 2005).

Até o momento, muitos estudos de identificação de risco tem sido direcionados para situações onde existe um contraste suficiente entre expostos e controles que permita a utilização de amostras relativamente pequenas ( $\mathrm{n}<100$ indivíduos) (BONASSI et al. 2005). Entretanto, pesquisas direcionadas ao estudo de relações dose-resposta, especialmente em situações de baixos niveis de exposição, demandam um tamanho amostral maior. Nestas condições, a logistica a cerca do processamento de sangue pode tornar-se complexa, sendo algumas vezes necessário a criopreservação do sangue total ou dos linfócitos isolados para análise posterior (BONASSI et al. 2005). Um estudo recente demonstrou a 
recuperação de linfócitos viáveis de sangue total criopreservado (HAYES et al. 2002), enquanto que outros têm demonstrado sucesso apenas na criopreservação de linfócitos isolados (BECK et al. 2001). Entretanto, foi demonstrado que a criopreservação das amostras pode induzir o incremento de $A C$ e diminuir a viabilidade celular (CHENG et al. 2001), o que pode causar um efeito adverso sobre o estudo.

O uso de $A C$ e MN em estudos de coorte prospectivos, adequados para validação por fornecerem informações importantes relativas a causalidade na relação dose-resposta, tem sido aplicado de modo limitado. Ambos os biomarcadores podem teoricamente ser utilizados como parâmetros intermediários para avaliação de dose-resposta, mas sua principal aplicação usualmente é como parâmetro para validar a avaliação de exposição (BONASSI et al. 2005).

Enquanto os estudos de coorte possuem a coleta seriada de amostras através do tempo como uma vantagem teórica, na prática, estudos muito longos impõem limitações quanto à coleta e preservação de amostras, o que traz algumas restrições. As AC e $M N$ assim como as principais aberrações genéticas refletem apenas os últimos meses de exposição, podendo não apresentar representatividade para a exposição e/ou doença em consideração (BONASSI et al. 2005). Neste caso, o estudo de translocações pode ser mais adequado, pois são alterações genéticas que persistem por décadas (TUCKER 2002).

Estudos de coorte com $\mathrm{AC}$ e MN como paråmetros precoces de risco de câncer em populações humanas têm sido realizados principalmente pelo 
método ad hoc (BONASSI et al. 1995; SMERHOVSKY et al. 2001), que são estudos realizados a partir de amostras obtidas de vários pequenos estudos de biomonitoramento, onde as principais limitações são as diferenças quanto às técnicas analíticas adotadas em cada estudo e a falta de informações detalhadas sobre os fatores de confusão e possiveis efeitos específicos nas populações amostradas (BONASSI et al. 2005).

Segundo BONASSI et al. (2005), dois fatores principais direcionam a crescente expansão da aplicação de biomarcadores citogenéticos. 0 primeiro é a inovação tecnológica. Seguindo o decréscimo no uso dos antigos biomarcadores de dano cromossômico, o desenvolvimento das técnicas analíticas têm transformado as aplicações de ensaios que inicialmente limitavam-se apenas ao monitoramento de exposições e agora podem ser usados como ferramentas altamente específicas capazes de fornecer valiosos insights sobre estágios precoces de doenças crônicas, especialmente o câncer (BONASSI et al. 2005).

De maneira similar, o potencial para estudar células interfásicas tem transformado o ensaio $\mathrm{MN}$, não apenas em um teste rápido e simples para genotoxicidade, mas também em uma ferramenta para avaliar eventos importantes como a amplificação gênica (TORAASON et al. 2004).

As vantagens mais evidentes esperadas para os próximos anos são o aumento da confiabilidade na avaliação de exposição e na detecção de danos precoces em populações expostas tanto a niveis reduzidos quanto a misturas complexas de agentes genotóxicos (BONASSI et al. 2005). A identificação de variações genéticas ligadas a danos cromossômicos está 
aumentando a sensibilidade e o poder destes estudos. Estas realizações serão facilitadas pela redução de custos das técnicas moleculares e pelo aumento do uso de automação, que tornarão exeqüiveis os estudos de grandes populações, aumentando assim a sensibilidade para detecção de efeitos de exposição (BONASSI et al. 2005).

O segundo aspecto que tem contribuído para o sucesso dos biomarcadores citogenéticos é sua validação como parâmetros precoces na predição de câncer (BONASSI et al. 2005). A relação causal entre AC e risco de câncer tem sido descrita em vários estudos de coorte (BONASSI et al. 2004). Um grande estudo internacional de coorte sobre a associação de freqüência de $\mathrm{MN}$ em indivíduos saudáveis e incidência de câncer está em desenvolvimento a alguns anos (FENECH et al. 1999), e em breve será finalizado. Outros estudos internacionais que também incluem avaliações por coorte para avaliação de efeitos de exposição ambiental a agentes químicos, em especial através do ar poluído, são o AULIUS Project e o EXPOLIS ${ }^{8}$, ambos realizados em países europeus.

Alguns estudos internacionais têm sido direcionados a investigação de efeitos de poluentes ambientais em crianças, visto que estas fazem parte do grupo de maior risco, considerando a elevada suscetibilidade que apresentam.

Em duas recentes revisões, NERI et al. $(2005 a, b)$ demonstraram que os biomarcadores de dano genético são capazes de detectar efeitos biológicos precoces em crianças e recém-nascidos expostos a poluentes do

\footnotetext{
${ }^{8}$ www.ktl.fi/expolis
} 
ar ambiente. Esses biomarcadores apresentaram um aumento consistente para exposições pré-natais e pós-natais à fumaça de cigarro e em exposições pós-natais a poluentes do ar urbano. Estes autores sugerem que os programas de biomonitoramento serão muito beneficiados pela inclusão de biomarcadores. A deteç̧ão de alterações dos biomarcadores poderá ser usada como uma evidência consistente e biologicamente fundamentada para a identificação de prioridades de intervenção em saúde ambiental direcionada a proteção da saúde da criança (NERI et al. 2005a).

$\mathrm{Na}$ última década, estudos epidemiológicos moleculares forneceram novas perspectivas aos estudos de riscos ambientais em populações pediátricas, fundamentando cada vez mais o fato já amplamente reconhecido de que as crianças podem ser mais suscetiveis a tóxicos do que adultos (NERI et al. 2005b). Proteção à saúde de crianças é uma prioridade social em muitos locais, como EUA e Europa, onde programas especificos de pesquisa têm sido iniciados com esse objetivo. Entre os vários objetivos destes programas, destacam-se o desenvolvimento de ferramentas específicas para interpretação e validação de biomarcadores e de métodos para extrapolação dos resultados dos biomarcadores em estratégias de intervenção e integração com dados de monitoramento ambiental (NERI et al. 2005b).

Durante a realização dos levantamentos bibliográficos para execução desta dissertação, nenhum projeto ou proposta semelhante às acima descritas foi encontrado em desenvolvimento no Brasil. 
A aplicação de biomarcadores citogenéticos na predição de risco de câncer em indivíduos saudáveis é um desafio considerável. A grande incerteza na predição de risco em nivel individual e a complexidade dos temas éticos talvez atrasem o desenho e planejamento de estudos de caracterização individual para câncer com esses ensaios (BONASSI et al. 2005). Apesar disso, já é possível a adoção de biomarcadores validados em políticas de prevenção e em programas de caracterização de efeitos em populações em grande risco, devido à exposição exógena ou a predisposição genética. Estes parâmetros ( $A C$ e $M N$ ) já estão suficientemente fundamentados para serem aplicados a estudos transversais para caracterização de efeitos carcinogênicos precoces (BONASSI et al. 2005).

A aplicação de biomarcadores citogenéticos para screening de indivíduos é de primordial importância, uma vez que representam o próximo passo necessário para estabelecer programas de vigilância em regulamentações nacionais para segurança ocupacional e ambiental (BONASSI et al. 2005). 


\section{CONCLUSÕES}

A aplicação de biomarcadores aos processos de avaliação de risco ambiental, em especial à saúde humana, tem-se ampliado continuamente. Os biomarcadores são aplicados há vários anos como parâmetros intermediários para extrapolações de dados entre efeitos em modelos animais e humanos, fundamentado a determinação de parâmetros de concentração e exposição ambiental. Mais recentemente, verificou-se uma ampliação desta aplicação. Os biomarcadores estão sendo utilizados como parâmetros intermediários também na avaliação de situações especificas. Tal aplicação tem-se mostrado possivel graças aos avanços obtidos nos estudos que visam à caracterização e validação de biomarcadores. Ainda que esses estudos tenham gerado uma quantidade significativa de informações que fundamentem sua utilização, devem ser adotados critérios consistentes quanto aos estudos de caracterização prévia da área e população de estudo para que os biomarcadores possam ser utilizados de maneira adequada e produzir informações confiáveis.

Entre os estudos recentes sobre validação de biomarcadores de HPA, pode-se verificar que, entre os biomarcadores disponiveis para avaliação em humanos expostos a HPA, destacam-se como metodologia já validada para monitoramento de exposição, a aplicação do 1-hidroxipireno urinário e como marcador de dose efetiva os adutos HPA-DNA em linfócitos. Entre os biomarcadores mais promissores até o momento, ainda em processo de 
validação, destacam-se como marcadores citogenéticos de efeito precoce a avaliação de freqüência de $A C$ e de indução $M N$.

As perspectivas para aplicação futura dos biomarcadores para avaliação de risco ambiental de exposições a HPA são promissoras. Os avanços esperados para os próximos anos são: 1) o aumento da confiabilidade na avaliação de exposição e na detecção de danos precoces em populações expostas tanto a niveis reduzidos quanto a misturas complexas de agentes genotóxicos; 2) aumento da sensibilidade destes estudos pela identificação de variações genéticas ligadas a danos cromossômicos; 3) redução de custos das técnicas moleculares e aumento do uso de automação, o que facilitará a adoção desta abordagem de estudo. 


\section{CONSIDERAÇÕES FINAIS}

Apesar dos biomarcadores mostrarem-se uma das abordagens mais promissoras como auxílio à avaliação de riscos, sua aplicabilidade tem sido questionada, principalmente devido à necessidade de desenvolvimento de estudos de validação, necessários para que os dados obtidos tenham a relevância necessária para interferir nos processos decisórios de gestão ambiental.

Mesmo após sua validação, biomarcadores necessitam de estudos de caracterização, sendo necessária a construção de dados referenciais específicos para cada situação. Este requisito dificulta sua adoção, uma vez que para sua correta elaboração são necessários profissionais de diferentes áreas de conhecimento, considerando que biomarcadores atuam de maneira interdisciplinar, o que requer obrigatoriamente a mesma abordagem para sua aplicação e análise. Esta visão permite uma fundamentação maior quanto à relevância dos estudos, entretanto, traz impedimentos, considerando-se o custo que envolve a efetivação dos estudos de validação e caracterização e a formação, treinamento e articulação de um corpo técnico interdisciplinar.

O uso dos biomarcadores, quando confrontado com os métodos atuais baseados na definição de padrões que apontam limites máximos de exposição a agentes químicos, pode, em um primeiro momento, ser de aplicação mais difícil e de custo mais elevado. Entretanto, as medidas de concentrações ambientais, embora importantes como ponto de partida da 
análise, permitindo uma visão ampla quanto à magnitude do impacto em relação à concentração do agente químico e oferecendo uma certa facilidade nas decisões, por consistirem em valores mundialmente reconhecidos, não consideram as especificidades locais, como a presença de populações suscetíveis, a interação entre diferentes agentes químicos e as características físico-químicas diferenciais do ambiente analisado e, principalmente, não garantem a inexistência de efeitos adversos.

Apesar das dificuldades em se desenvolver os estudos de caracterização, em especial no Brasil, onde os recursos e a estrutura disponivel são limitados, deve-se salientar que a possibilidade de entendimento das especificidades locais é justamente o maior avanço que os biomarcadores fornecem. Entretanto, sua caracteristica de interdisciplinaridade requer necessariamente a mesma abordagem para sua correta interpretação, o que pode se contrapor à estrutura tradicional centralizadora, ainda muito presente em muitos processos de gestão ambiental.

A maior fonte de informações sobre efeitos de agentes químicos em humanos é o estudo de exposições ocupacionais, pois, por motivos éticos, exposições experimentais não podem ser realizadas. Entretanto, este padrão de exposição (usualmente altas concentrações de um ou poucos agentes químicos em um intervalo de tempo relativamente curto) não coincide com o padrão de exposição ambiental (usualmente baixas concentrações de muitos agentes químicos em um longo intervalo de tempo) e por este motivo, nem sempre é possivel extrapolar dados entre estes 
diferentes padrões, sendo necessários estudos para definição de critérios que permitam essas extrapolações.

Entre os biomarcadores mais promissores até o momento, disponiveis para avaliação em humanos expostos a HPA, destacam-se como marcador de exposição o 1-hidroxipireno urinário e como marcador de dose efetiva os adutos HPA-DNA em linfócitos circulantes. Para avaliação de risco de câncer após exposições aos HPA, destacam-se, entre os marcadores citogenéticos, a avaliação de freqüência de Aberrações Cromossômicas (AC) e de indução de Micronúcleo (MN).

Considerando as vantagens e desvantagens do monitoramento biológico e ambiental para definir exposição a compostos aromáticos, incluindo os HPA, os adutos de DNA possuem algumas vantagens sobre as metodologias tradicionais, que são (GODSCHALK et al. 2003): 1) adutos de DNA são considerados como tendo papel significante na causa de alguns tipos de câncer e representam uma medida de exposição assim como de risco; 2) estas análises podem contribuir para diminuir as incertezas da variabilidade extrema de exposição, típico nas exposições a agentes químicos ambientais, permitindo uma diminuição dos esforços de monitoramento físico-quimico; 3) essa avaliação considera as múltiplas rotas de ingresso; 4) podem demonstrar as diferenças interindividuais nos processos de ingresso, eliminação, distribuição, metabolismo e reparo em indivíduos expostos.

Por outro lado, limitações analíticas como as imprecisões do ensaio podem contribuir significativamente para erros de medição. Desta forma, 
futuros progressos na aplicação de adutos de DNA dependem do desenvolvimento e uso sistemático de técnicas analíticas de alta resolução, como eletroforese capilar combinada à detecção de fluorescência ou espectrometria de massa (GODSCHALK et al. 2003).

O entendimento das relações entre dose-resposta e a persistência de adutos é indispensável para os estudos de monitoramento de exposições que usem adutos de DNA como parâmetro, fornecendo informações sobre de que forma e com que velocidade os niveis de adutos podem mudar em resposta a mudanças nos padrões de exposição. As variações intra e interindividuais devem ser caracterizadas antes que os adutos de HPA-DNA possam ser aplicados como marcadores de exposição em estudos de larga escala. Entre os principais fatores associados à variação interindividual, destaca-se o polimorfismo genético das enzimas envolvidas na detoxificação de HPA e no mecanismo de reparo do DNA.

Para a caracterização de biomarcadores para avaliação de indução de carcinogênese, estão sendo utilizados estudos transversais para avaliar os efeitos de dano ao DNA resultantes de uma ampla gama de exposições, incluindo os HPA. Nestes estudos, os principais parâmetros intermediários utilizados são a freqüência de $A C$ e de indução de MN. Apesar de não permitirem a determinação de causalidade entre exposição e carcinogênese, estes estudos transversais têm fornecido informações importantes quanto ao mecanismo que envolve a relação exposição-doença, auxiliando a formulação de uma base teórica mais fundamentada para realização futura de estudos longitudinais prospectivos, mais adequados para validação. 
Levando-se em consideração as limitações e os avanços que estes biomarcadores apresentam, recomenda-se como complemento às análises físico-químicas já utilizadas para determinação de concentrações ambientais de agentes quimicos, a utilização integrada de biomarcadores de dose interna e efetiva para diminuição das incertezas das estimativas de exposição; para determinação de dose interna de HPA o 1-hidroxipireno urinário e para dose efetiva os adutos de DNA-HPA. Visando diminuir as incertezas relativas a variações interindividuais devido a diferenças genéticas, recomenda-se a adoção conjunta de caracterização de polimorfismo genético, objetivando a identificação do padrão genético da população estudada, em especial quanto aos genes responsáveis pela produção de enzimas de detoxificação e reparo de danos ao DNA.

Em complemento a estes estudos acima citados, recomenda-se também, a verificação de alterações citogenéticas, como quebras cromossômicas, micronúcleo e aberrações cromossômicas, como biomarcadores de efeito precoce, que, mesmo ainda não validados, podem fornecer informações importantes para avaliação dos mecanismos envolvidos no desenvolvimento de doenças, em especial o câncer.

Esta utilização integrada de biomarcadores, em um momento inicial deve visar à caracterização do cenário de estudo, fornecendo informações para construção de um banco de dados referenciais.

Em um segundo momento, quando já disponivel uma quantidade suficiente de informações que permitam a caracterização da população de estudo quanto ao padrão de exposição, constituição genética e principais 
efeitos precoces observados, devem-se desenvolver estudos observacionais (epidemiológicos). Estes estudos epidemiológicos associados às informações previamente obtidas permitirão a verificação da ocorrência de correlações e associações entre o padrão de exposição e os efeitos precoces e possíveis efeitos tardios, como câncer ou outras doenças. Tais indicios de causalidade poderão, então, fundamentar ações regulatórias como os limites de emissão de poluentes para exposição humana, ambiental ou ocupacional.

A análise da literatura recente demonstra que, de maneira geral, já existem dados que fundamentem a adoção deste modelo de avaliação integrada de biomarcadores em série acima citado.

Apesar das dificuldades quanto à aplicação de biomarcadores, devese considerar que a prevenção ainda continua sendo a forma mais eficiente de atenção à saúde, pois muitos danos quando estabelecidos, dificilmente podem ser recuperados em sua totalidade. Associado a isso deve-se considerar que o custo elevado para a adoção de medidas de mitigação de impactos muitas vezes inviabiliza sua implementação. É importante destacar que os biomarcadores representam perspectivas importantes para a ampliação das pesquisas científicas no campo da saúde ambiental e da saúde pública. Em todo mundo é crescente o investimento em pesquisas científicas voltadas à identificação, avaliação e validação de biomarcadores para uso em avaliações de riscos de exposições ambientais. No Brasil, entretanto, estes estudos ainda são muito incipientes. 
Os estudos de biomarcadores podem fornecer informações relevantes para a melhoria efetiva da qualidade ambiental e de saúde, bem como para a preservação dos ecossistemas nacionais. Assim, é importante o investimento em estudos específicos para o desenvolvimento e a validação de biomarcadores adequados à realidade brasileira, considerando-se as características ambientais, econômicas e sociais regionais.

O Brasil já acumula uma experiência de mais de 20 anos de aplicação da Política Nacional de Meio Ambiente, baseada essencialmente no enquadramento a padrões de emissão de poluentes e de qualidade ambiental estabelecidos. Neste período, as ações, programas e investimentos desenvolvidos têm sido marcados pela busca do atendimento aos objetivos dessa Política, como a principal forma de garantir a preservação da saúde humana e a proteção dos ecossistemas.

Nesse contexto, o estudo dos biomarcadores configura-se como uma ferramenta importante para a checagem da efetividade ou não dos padrões estabelecidos, possibilitando a avaliação e adequação de seus valores, fornecendo respostas mais confiáveis sobre as condições da saúde humana e dos ecossistemas. 


\section{REFERÊNCIAS}

Aardema MJ e MacGregor JT. Toxicology and genetic toxicology in the new era of "toxicogenomics": impact of "-omics" technologies. Mutation Research Frontiers, 2002; 499:13-25.

Albertini RJ, Anderson D, Douglas GR, Hagmar L, Hemminki K, Merlo F, Natarajan AT, Norppa H, Shuker DE, Tice R, Waters MD, Aitio A. IPCS guidelines for the monitoring of genotoxic effects of carcinogens in humans. Mutat Res 2000; 463:111-172.

Albertini, RJ. Developing sustainable studies on environmental health. Mutat Res $2001 ; 480-481: 317-31$.

[ATSDR] Agency for Toxic Substances and Disease Registry. Toxicological Profile for Polycyclic Aromatic Hydrocarbons. Atlanta; 1995.

Au WW, Oh HY, Grady J, Salama SA, Heo MY. Useflilness of genetic susceptibility and biomarkers for evaluation of environmental health risk. Environ Mol Mut 2001; 37:215-225.

Autrup H. Genetic polymorphisms in human xenobiotic-metabolizing enzymes as susceptibility factors in toxic response. Mutat Res 2000; 464: 65-76.

Ballaroti $\mathrm{N}$ e Villalobos A. Defining the Molecular and Cellular Basis of Toxicity Using Comparative Models. Toxicology and Applied Pharmacology 2002; 183:207-220.

Bartsch H, Nair U, Risch A, Rojas M, Wikman H, Alexandrov K. Genetic polymorphism of CYP genes, alone or in combination, as a risk modifier of tobacco-related cancers. Cancer Epidemiol Biomarkers Prev 2000; 9:328.

Beck JC, Beiswanger CM, John EM, Satariano E, West D. Successful transformation of cryopreserved lymphocytes: a resource for epidemiological studies. Cancer Epidemiol Biomarkers Prev 2001; 10:551-554.

Behnisch PA, Hosoe K, Sakai S. Bioanalytical screening methods for dioxins and dioxin-like compounds - a review of bioassay/biomarker technology. Environment International 2001; 27:413-439.

Besaratinia A, Maas LM, Brouwer EM, Kleinjans JC e Van Schooten FJ. Comparison between smokingrelated DNA adduct analysis in induced sputum and peripheral blood lymphocytes. Carcinogenesis 2000; 21:13351340. [errata publicada em Carcinogenesis 2005; 26:1160]. 
BIBCIR/FSP - Biblioteca da Faculdade de Saúde Pública da USP. Guia de Apresentação de Teses: Manual técnico[online]. Disponivel em $<w w w . b v s-s p . f s p . u s p . b r: 8080 / \mathrm{html} / \mathrm{pt} /$ paginas/biblioteca/guia_teses.html> [24 nov 2005].

Bonassi S, Abbondandolo A, Camurri L, Dal Prá A, De Ferrari M, Degrassi F, Forni A, Lamberti L, Lando C, Padovani P, Sbrana I, Vecchio D, Puntoni R. Are chromosome aberrations in circulating lymphocytes predictive of a future cancer onset in humans? Preliminary results of an Italian cohort study. Cancer Genet Cytogenet 1995; 79:133-135.

Bonassi S, Neri M, Puntoni R. Validation of biomarkers as early predictors of disease. Mutation Research 2001; 480:349-358.

Bonassi S, Au WW. Biomarkers in molecular epidemiology studies for health risk prediction. Mutation Research 2002; 511: 73-86.

Bonassi S, Ugolini D, Kirsch-Volders M, Stromberg U, Vermeulen R, Tucker JD. Human population studies with cytogenetic biomarkers: Review of the literature and future prospectives. Environ Mol Mutagen 2005; 45:258-270.

Brandt HC, Watson WP. Monitoring human occupational and environmental exposures to polycyclic aromatic compounds. Ann Occup Hyg 2003; 47:349-78.

Brescia G, Celotti L, Clonfero E, Neumann HG, Forni A, Foá V, Pisoni M, Ferri GM, Assennato $G$. The influence of cytochrome P450 $|A|$ and glutathione S-transferase M1 genotypes on biomarker levels in coke-oven workers. Arch Toxicol 1999; 73:431-439.

Burchiel SW e Luster MI. Signaling by environmental polycyclic aromatic hydrocarbons in human lymphocytes. Clinical Immunology 2001; 98:2-10.

Cheng L, Wang LE, Spitz MR, Wei Q. Cryopreserving whole blood for functional assays using viable lymphocytes in molecular epidemiology studies. Cancer Lett 2001; 166:155-163.

Dallinga JW, Pachen DM, Wijnhoven SW, Breedijk A, van't Veer L, Wigbout G, van Zandwijk N, Maas LM, van Agen E, Kleinjans JC e van Schooten FJ. The use of 4-aminobiphenyl hemoglobin adducts and aromatic DNA adducts in lymphocytes of smokers as biomarkers of exposure. Cancer Epidemiol Biomarkers \& Prev 1998; 7:571-577.

De Flora S, Izotti A, D'Agostini F, Rossi GA, Balansky RM. Pulmonary alveolar macrophages in molecular epidemiology and chemoprevention of cancer. Environ Health Perspect 1993; 99:249-252. 
Depledge $\mathrm{MH}$ e Fossi MC. The role of biomarkers in environmental assessment. Ecotoxicology 1994; 3(2):161-172.

Dor F, Empereur-Bissonnet, Zmirou D, Nedellec V, Haguenoer JM, Jongeneelen F, Person A, Dab W, Fergusson C. Validation of multimedia models assessing exposure to PAHs - the SOLEX study. Risk Analysis 2003; 23:1047-1057.

Dubé $M$ e Munkittrick $K$. Integration of effect-based and stressor-based approaches into a holistic framework for cumulative effects assessment in aquatic ecossystems. Human and Ecological Risk Assessment 2001; 7:247-258.

Eason $\mathrm{C}$ e O'Halloran K. Biomarker in toxicology versus ecological risk assessment. Toxicology 2002; 181-182:517-521.

Ehrenberg L, Granath F, Törnqvist E. Macromolecular adducts as biomarkers of exposure to environmental mutagens in human populations. Environ Health Perspect; 1996; 104(3):423-428.

Fenech M, Holland N, Chang WP, Zeiger E, Bonassi S. The human micronucleus project: an international collaborative study on the use of the micronucleus technique for measuring DNA damage in humans. Mutat Res 1999; 428:271-283.

Franzini A. Estudo de procedimentos para avaliação dos riscos para a saúde humana em áreas contaminadas por substancias perigosas. São Paulo; 2005. [Dissertação de mestrado - Faculdade de Saúde Pública da USP].

Garte S. Metabolic susceptibility genes as cancer risk factors: time for a reassessment. Cancer Epidemiol Biomarkers Prev 2001; 10:1233-1237.

Godschalk RW, Van Schooten FJ, Bartsch H. A critical evaluation of DNA adducts as biological markers for human exposure to polycyclic aromatic compounds. J Biochem Mol Biol 2003; 36:1-11.

Handy RD, Galloway TS e Depledge MH. A proposal for the use of biomarkers for the assessment of chronic pollution and in regulatory toxicology. Ecotoxicology 2003; 12(1-4):331-43.

Hansen AM, Wallin $H$, Binderup ML, Dybdahl $M$, Autrup $H$, Loft $S$, et al. Urinary 1-hydroxypyrene and mutagenicity in bus drivers and mail carriers exposed to urban air pollution in Denmark. Mutat Res 2004; 557:7-17.

Hayes RB, Smith CO, Huang WY, Read Y, Kopp WC. Whole blood cryopreservation in epidemiological studies. Cancer Epidemiol Biomarkers Prev 2002; 11:1496-1498. 
Heinrich U, Roller M, Pott F. Estimation of a lifetime unit lung cancer risk for benzo(a)pyrene based on tumor rates in rats exposed to coal tar pitch condensation aerosol. Toxicol Lett; 1994; 72:155-61.

Herbert R, Marcus M, Wolff MS, Perera FP, Andrews L, Godbold JH, Rivera $M$, Stefanidis M, Lu XQ, Landrigan PJ e Santella RM. Detection of adducts of deoxyribonucleic acid in white blood cells of roofers by 32P-postlabeling. Relationship of adduct levels to measures of polycyclic aromatic hydrocarbons. Scand J Work Environ Health 1990; 16:135-143.

Hung RJ, Boffetta P, Brockmöller J, Butkiewicz D, Cascorbi I, Clapper ML, Garte S, Haugen A, Hirvonen A, Anttila S, Kalina I, Le Marchand L, London SJ, Rannug A, Romkes M, Salagovic J, Schoket B, Gaspari L, Taloli E. CYP1A1 and GSTM1 genetic polymorphisms and lung cancer risk in Caucasian non-smokers: a pooled analysis. Carcinogenesis 2003; 24:875882.

Ichiba M. Hagmar L, Rannug A, Högstedt B, Alexandrie A-K, Carstensen U, Hemminki K. Aromatic DNA adducts, micronuclei and genetic polymorphism for CYP1A1 and GST in chimney sweeps. Carcinogenesis 1994; 15:13-52.

Jacob $\mathrm{J}$ e Seidel A. Biomonitoring of polycyclic aromatic hydrocarbons in human urine. Journal of Chromatography B 2002; 778:31-47.

Jekel JF, Elmore JG, Katz DL. Epidemiologia, bioestatística e medicina preventiva. Porto Alegre: ARTMED, 2002.

Jongeneelen FJ, Methods for routine biological monitoring of carcinogenic PAH-mixtures. Sci Total Environ; 1997; 199:141-149.

Jongeneelen FJ. Benchmark guideline for urinary 1-hydroxypyrene as biomarker of occupational exposure to polycyclic aromatic hydrocarbons. Ann Occup Hyg 2001; 45:3-13.

Knudsen LB, Norppa H, Gamborg MG, Nielsen PS, Okkels H, Soll-Johanning $H$, Raffli $E$, Järventaus $H$, Autrup $H$. Chromosomal aberrations induced by urban air pollution in humans: influence of DNA repair and polymorphisms of glutathione $\mathrm{S}$-transferase $\mathrm{M} 1$ and $\mathrm{N}$-acetyltransferase 2. Cancer Epidemiol Biomarkers Prev 1999; 8:303-310.

Law RJ e Biscaya JL. Polycyclic Aromatic Hydrocarbons (PAH) - problems and progress in sampling, analysis and interpretation. Mar Pollut Bull 1994; 29:235-241.

Mitelman F, Johansson B, Mertens F. Fusion genes and rearranged genes as a linear function of chromosome aberrations in cancer. Nat Genet 2004; 36:331-334. 
Molak $\mathrm{V}$ [editor]. Fundamentals of risk analysis and risk management. Cincinnati; Lewis Publishers; 1996.

Moore MN, Depledge MH, Readman JW, Paul Leonard DR. An integrated biomarker-based strategy for ecotoxicological evaluation of risk in environmental management. Mutation Research 2004; 552:247-268.

[NAS] National Academy of Sciences. Risk assessment in the federal government: managing the process. National Academy Press, EUA; 1983.

Neri M, Bonassi S, Knudsen LE, Sram RJ, Holland N, Ugolini D, Merlo DF. Children's exposure to environmental pollutants and biomarkers of genetic damage I. Overview and critical issues. Mutation Research ARTICLE IN PRESS 2005a.

Neri M, Ugolini D, Bonassi S, Fucic A, Holland N, Knudsen LE, Sram RJ, Ceppi M, Bocchini V, Merlo DF. Children's exposure to environmental pollutants and biomarkers of genetic damage $\mathrm{I}$. Overview and critical issues. Mutation Research ARTICLE IN PRESS 2005b.

Norppa $\mathrm{H}$. Cytogenetic biomarkers and genetic polymorphisms. Toxicology Letters 2004; 149:309-334.

[OMS] Organização Mundial da Saúde. International Programme on Chemical Safety (IPCS). Selected non-heterocyclic Polycyclic Aromatic Hydrocarbons. Genebra; 1998. [Environmental Health Criteria, 202].

[OMS] Organização Mundial da Saúde. International Programme on Chemical Safety (IPCS). Biomarkers and risk assessment: validity and validation. Genebra; 2001. [Environmental Health Criteria, 222].

Pacchierotti F, Adler ID, Anderson D, Brinkworth M, Demopoulos NA, Lähdetie J, Osterman-Golkar S, Peltonen K, Russo A, Tates A, Waters R. Genetic effects of 1,3-butadiene and associated risk for heritable damage. Mutat Res 1998; 397:93-115.

Payne JF, Fancey LL, Rahimtula AD, Porter EL. Review and perspective on the use of mixed-function oxygenase enzymes in biological monitoring. Comp Biochem Physiol 1987; 86C:233-245.

Peluso M, Ceppi M, Munnia A, Puntoni R, Parodi S. Analysis of 13 32Ppostlabeling studies on occupational Cohorts exposed to air pollution. Am J Epidemiol 2001; 153:546-558.

Phillips DH, Schoket B, Hewer A, Bailey E, Kostic S e Vincze I. Influence of cigarette smoking on the levels of DNA adducts in human bronchial epithelium and white blood cells. Int J Cancer, v. 46, p. 569-575, 1990. 
Phillips DH, Farmer PB, Beland FA. Methods of DNA adduct determination and their application to testing compounds for genotoxicity. Environ Mol Mutagen 2000; 35:222-33.

Pivetta F, Machado JMH, Araújo UC, Moreira MFR, Apostoli P. Monitoramento biológico: conceitos e aplicações em saúde pública. Cad. Saúde Pública 2001; 17:545-554.

Schoket B, Papp G, Levay K, Mrackova G, Kadlubar FF, Vincze I. Impact of metabolic genotypes on levels of biomarkers of genotoxic exposure. Mutat Res 2001; 482(1-2):57-69.

Schulte PA e Perera FP. Molecular Epidemiology Principles and Practices, Academic Press, San Diego, 1993.

Schulte, PA. Opportunities for the development and use of biomarkers. Toxicol Lett 1995; 77(1-3):25-9.

Silbergeld EK. Neurochemical approaches to developing biochemical markers of neurotoxicity: review of current status and evaluation of future prospects. Environ Res; 1993; 63:274-286.

Siwinska E, Mielzynska D, Kapka L. Association between urinary 1hydroxypyrene and genotoxic effects in coke oven workers. Occup Environ Med 2004; 61:1-10.

Smerhovsky Z, Landa K, Rössner P, Brabec M, Zudova Z, Hola N, Pokoma $Z$, Mareckova J, Hurychova D. Risk of cancer in an occupationally exposed cohort with increased level of chromosomal aberrations. Environ Health Perspect 2001; 109:41-45.

Smerhovsky Z, Landa K, Rössner P, Juzova D, Brabec M, Zudova Z, Hola N, Zarska $\mathrm{H}$, Nevsimalova $E$. Increased risk of cancer in radon-exposed miners with elevated frequency of chromosomal aberrations. Mutat Res 2002; 514:165-176.

Sorensen MAH, Moller P, Hertel O, Jensen SS, Vinzents P, Knudsen LE, Loft S. Linking exposure to environmental pollutants with biological effects. Mutat Res 2003; 544(2-3):255-71.

Spaling $\mathrm{H}$ e Smit $\mathrm{B}$. Cumulative environmental change: Conceptual frameworks, evaluation approaches and institutional perspectives. Environ Management 1993; 17:587-600.

Šrám R, Birkova B, Rössner P, Rubes J, Topinka J, Dejmek J. Adverse reproductive outcomes from exposure to environmental mutagens. Mutat Res 1999; 428:203-215. 
Strange RC, Jones, PW, Fryer, AA. Glutathione S-transferase: genetics and role in toxicology. Toxicol Lett 2000; 112-113, 357-363.

Suter, G.W. Ecological Risk Assessment. Lewis Publishers,Boca Raton, FL, USA, 1993.

Symanski E, Greeson NMH. Assessment of variability in biomonitoring data using a large database of biological measures of exposure. AlHA Journal 2002; 63:390-401.

Szklo M e Nieto FJ. Epidemiology, Beyond the basis. Aspen Publication, 2000.

Toraason M, Albertini R, Bayard S, Bigbee W, Blair A, Boffetta P, Bonassi S, Chanock S, Christiani D, Eastmond D, Hanash S, Henry C, Kadlubar F, Mirer F, Nebert D, Rapport S, Rest K, Rothman N, Ruder A, Savage R, Schulte P, Siemiatycki J, Shields $P$, Smith $M$, Tolbert $P$, Vermeulen $R$, Vineis $P$, Wacholder S, Ward E, Waters M, Weston A. Applying new biotechnologies to the study of occupational cancer: a workshop summary. Environ Health Perspectives 2004; 112:413-416.

Tsai PJ, Shih TS, Chen HL, Lee WJ, Lai CH, Liou SH. Urinary 1hydroxypyrene as an indicator for assessing the exposures of booth attendants of a highway toll station to polycyclic aromatic hydrocarbons. Environ Sci Technol 2004; 38(1):56-61.

Tucker JD. Sensitivity, specificity, and persistence of chromosome translocations for radiation biodosimetry. Mil Med 2002; 167:8-9.

Van Leeuwen CJ, Hermens JLM. Risk Assessment of Chemicals: an Introduction. Kluwer Academic Publishers, Dordrecht, Holanda, 1995.

Van der Oost R, Beyer J, Vermeulen NPE. Fish bioaccumulation and biomarkers in environmental risk assessment: a review. Environmental Toxicology and Pharmacology 2003; 13:57-149.

Viau C, Lafontaine M, Payan JP. Creatinine normalization in biological monitoring revisited: the case of 1-hydroxypyrene. Int Arch Occup Environ Health 2004; 77(3):177-85.

Waters MD e Nolan C. EC/US workshop report: assessment of genetic risks associated with exposure to ethylene oxide, acrylamide, 1,3-butadiene and cyclophosphamide. Mutat Res; 1995, 330:1-11.

Wiencke JK, Kelsey KT, Varkonyi A, Semey K, Wain JC, Mark E, Christiani DC. Correlation of DNA adducts in blood mononuclear cells with tobacco carcinogen induced damage in human lung. Cancer Res 1995; 55:49104914. 
Wünsch Filho V, Gattás GJF. Biomarcadores moleculares em câncer: implicações para a pesquisa epidemiológica e a saúde pública. Cad Saúde Pública 2001; 17:467-480. 